Claudia Castillo (*)

Instituto de Estética

Facultad de Filosofía

Pontificia Universidad Católica de Chile

\title{
La fe en hojas "de a centavo". Prensa católica en Chile, sus lectores y el caso de El Mensajero del Pueblo, 1870-1876.
}

Camilo Henríquez, nacido en la ciudad de Valdivia y que contaba 43 años a la fecha de la publicación del primer periódico de Chile, quizás pudo vislumbrar lo que sería su actuación en el proceso del camino republicano chileno. Cuando comenzó a escribir sus estudios sobre ideas políticas independentistas es probable que haya entendido y anhelado el rol que sus palabras tendrían, pero no así imaginar el alcance de su actuación un siglo después. El 13 de febrero de 1812, en los albores del camino republicano nacional, la imprenta y un cura estarían aliados para la publicación no solo del primer periódico, sino de uno que hablaba de cómo debía ser la sociedad a inaugurar. Camilo Henríquez, elegido editor por el gobierno para promover las ideas independentistas, y en consecuencia, también como un claro representante de los proyectos republicanos, no volvería a tener un igual en la historia de Chile. Un cura para promover la idea de sociedad querida no fue nunca más una opción para los gobiernos que se sucedieron desde la Independencia.

Triple vínculo nada casual en las luchas independentistas, destello de una sociedad en la que religión y política, religión y sociedad, eran solvente y soluto indistinguibles en la mezcla final, pero que ahora nos importa por lo que pasó a representar. Cien años después, la jerarquía diocesana, lejos de recordar que Henríquez leyó a Rousseau y que fue vigilado por la Inquisición, se adueñó de este suceso y lo recordó rodeándolo de un simbolismo que debía infundir fuerzas para promover la publicación de periódicos (1). Señalaban que la Iglesia no debía permanecer indiferente en la celebración de "tan fausto centenario", "que es una gloria para el pensamiento nacional". La Aurora de Chile era el comienzo de "nuestra prensa", aludiendo a la prensa en Chile, una prensa por lo demás "tan equilibrada, tan respetuosa, tan digna y patriota".

(*) Agradezco a Sol Serrano, por todo; a María Elena Uriarte, por su ayuda; y al personal del Archivo Histórico del Arzobispado de Santiago de Chile, por su diligencia.

(1) "Circular a los párrocos sobre el primer centenario de La Aurora", 11 de febrero de 1912. En La Revista Católica, 17 de febrero de 1912, No 253, p. 250. 
El arzobispo Juan Ignacio González Eyzaguirre diagnosticó así al periodismo en Chile. Diagnóstico contradictorio si vemos la energía que gastaba en su lucha contra la "prensa impía", tanto en el documento del aniversario como en el itinerario de su actividad pastoral. Contradictorio con sus mismas órdenes del día, que junto con el repique de las campanas a las seis de la mañana, hora exacta en que apareció La Aurora, comprendían que los párrocos y rectores de iglesia hicieran alguna fiesta, "dando a conocer a los fieles el aniversario que celebramos, la importancia del periodismo y la obligación que todos tienen de inspirarse en la buena prensa". Contradictorio porque, si había lugar para una "buena prensa", es claro que no toda "nuestra prensa", es decir, no toda la prensa chilena, era "buena". Se trataba entonces de una circular que, a pesar de los deseos o ilusiones de la silla arzobispal, no promovería la actuación periodística de la nación, sino tan solo, la actuación periodística de los católicos.

\section{RENOMBRADA POR SUS CONTEMPORÁNEOS. ANÓNIMA PARA LA HISTORIOGRAFÍA}

Las consideraciones y órdenes del purpurado cobran otros alcances si las dimensionamos en su contexto. El siglo veinte nació con la promoción de la "buena prensa", de la "propaganda católica" o del "periodismo católico" por parte de la jerarquía, lo que no excluye la iniciativa de grupos de laicos católicos independientes de la autoridad eclesiástica (2). Por estos años, esta circular a los párrocos, tan inclusiva y festiva -a la vez que normativa-, quería fomentar decididamente las plumas católicas y se constituía en un llamado a la conciencia de cada "católico sincero". En Chile, este objetivo ya había sido vislumbrado por "personas de buena voluntad", actividad que sirvió de base para organizar la Sociedad de la Buena Prensa en 1906 y, en el ocaso del siglo previo, la sociedad de La Propaganda Católica recibió el sello oficial a sus Estatutos (3).

No obstante, desde 1812 a 1912 no habían pasado solo cien años, y las novedades no se remitían únicamente al ámbito del mercado, de la tecnología, de la educación y del remozamiento del cerro Santa Lucía. Entrelazadas, con unos más que con otros de los cambios anteriores, habían pasado también las disputas que llevaron a resquebrajar la Cristiandad, la unión de la Religión con el Estado, el cual si bien seguía siendo católico, ya no lo era del mismo modo. Ahora había

(2) Miranda Lida indica que en Argentina la prensa católica no actuaba como vocera de la autoridad eclesiástica. De hecho, señala que "ninguno de los periódicos del periodo se halla bajo la directa dependencia del titular de la sede eclesiástica porteña, sino que la mayoría de las veces los periódicos se hallaban administrados por laicos". Ver su trabajo "Prensa católica y sociedad en la construcción de la Iglesia argentina en la segunda mitad del siglo XIX" en Anuario de Estudios Americanos, 63 (1), Sevilla (España), 2006, p. 73. También, "La prensa católica y sus lectores en Buenos Aires, 1880-1920" en Prismas. Revista de historia intelectual, Buenos Aires, Universidad Nacional de Quilmes, Número 9, 2005.

(3) Actas de fundación y estatutos en Archivo del Arzobispado de Santiago, legajo 60, número 82 y legajo 48, número 24. Los estatutos de la Sociedad de la Propaganda Católica se aprobaron el 25 de junio de 1894 . 
que apellidar a la "religión", y cuando se hablaba de las "religiones" ya no solo era para identificar a las distintas "Órdenes". El catolicismo era lo que ahora se diferenciaba de la sociedad.

En las primeras décadas del siglo veinte los tiempos habían cambiado tanto que los católicos se acostumbraron a hablar de batallas y de ejércitos pues, si bien estas palabras se habían pronunciado conjuntamente a los padres nuestros y las ave marías, ahora la cruzada y la lucha ya no era solo contra las pasiones personales, sino que se recurría rápidamente a las imágenes de la recuperación de Tierra Santa. Había que recuperar el terreno perdido. Tal como lo señalaría un participante del Congreso Social Católico de Puebla en México en 1903, la escuela y la prensa serían las alas izquierda y derecha del ejército católico (4). La actitud, que nació contra "el espíritu del siglo", que emergió como dique a la secularización entendida como caída y declive de la religión en la sociedad, pensamos que fue, visto ya no desde la perspectiva de los actores, un elemento que fomentó la separación y que definió al catolicismo como una entidad claramente diferenciable de otros credos religiosos y opiniones. Fue, en ese sentido, una actitud secularizadora entendida esta como separación y distinción de las esferas.

Las alas del cambio eran radicalmente nuevas. Se puede discutir si lo era o no la educación, pero sí lo fue en atención a cómo se definió en este nuevo terreno. Escuela y prensa eran militantes. La escuela católica aparecía y se proliferaba para que la sociedad no dejara de ser católica, nacía como estandarte de batallas y para la formación de ciudadanos "católicos" (5). La prensa aparecía con el mismo objeto. Se instalaría con fuerza en las primeras décadas del siglo veinte y las encíclicas y bendiciones papales llamarían a sostenerla con las limosnas pingües del rico y con los cobres del pobre, junto con fijar la forma en que se debía desarrollar.

Esta realidad, tan clara para sus actores y con tanta publicidad en el período, en la que se invirtieron cuantiosos recursos y no menos cuotas de imperativos categóricos, no encuentra atención en la mayor parte de la historiografía chilena. Prácticamente, no hay conclusiones de investigaciones históricas sobre prensa católica en Chile y menos de sus procesos y sus distinciones, aparte del reciente estudio de Patricio Bernedo con algunas de sus conclusiones a las investigaciones que lleva a cabo sobre La Revista Católica y El Estandarte Católico (6). El problema es mayor

(4) Ricardo Krebs, Historia de la Iglesia en Latinoamérica, Santiago, Universidad Católica, 2000.

(5) Estamos tomando la idea que hizo brotar el nacimiento de escuelas católicas desde sus gestores. No se ha realizado un estudio interpretativo global sobre el significado de las escuelas católicas, pero creemos que se le puede atribuir la misma idea que presentamos ahora para la prensa católica.

(6) El autor nos entrega una visión sobre el surgimiento de la prensa católica a partir de dos periódicos que visten el siglo XIX con la opinión del Arzobispado. Según Bernedo, el clero chileno habría hecho un fuerte diagnóstico que les permitió entender y usar las mismas herramientas de los liberales ingresando como un actor relevante en la opinión pública. No obstante, el artículo adolece de un análisis de circulación y lectores pues sabemos que La Revista Católica no tenía una amplia circulación y como señaló Crescente Errázuriz, la leían muy pocos. Ver "Usando las armas del adversario. Prensa e Iglesia en el Chile del siglo XIX" en Cuadernos de Información, $\mathrm{N}^{\mathrm{o}} 19$ (2006), pp. 102-108. Fuera de estos límites territoriales, hemos rastreado las huellas a las investigaciones de Dominique Marquis, "Un nouveau combat pour l'Église, la presse catholique d'information, 1907-1940" en Études d'histoire religieuse 68 (2002), pp. 63-88, pero su caso nos sirve solo por sus aplicaciones metodológicas. Mucho más relevantes son los trabajos de Miranda 
en relación a la prensa católica destinada al pueblo. Esta, ya sea de carácter masivo o bien hojas exclusivamente parroquiales, no aparece ni siquiera mencionada en la mayoría de los casos. Algunas investigaciones se han topado con ellas, pero las han abordado de modo tangencial a sus hipótesis principales. De hecho, la prensa popular se ha caracterizado por la historiografía como esencialmente socialista o anarquista (7), situación destacada por cualquier compendio de historia de Chile (8). La excepción, para todos, vendría a ser el diario católico El Chileno, conocido como "el diario de las cocineras" (9). Esta última publicación ha sido analizada entre 1892 y 1900 por Eduardo Santa Cruz, quien indica que el periódico pertenece a la misma línea de La Revista Católica, El Estandarte Católico y El Independiente, pero "lo distinto es, sin embargo, que El Chileno nace con el propósito explícito de dirigirse a un público popular" (10). Santa Cruz lo estudia no como prensa católica, sino como un paso en la modernización de las prácticas del periodismo. Por otro lado, Sergio Grez ha entregado nombres de periódicos que se habían escapado a los ojos de los distintos investigadores vinculándolos a todos como parte de un proceso de modernización de las prácticas politizadoras del pueblo (11). Los manuales de historia de la Iglesia destacan, aunque sin investigaciones monográficas y en un par de líneas o lánguidos párrafos, la labor de la prensa católica política, pero no consideran todos los alcances de los semanarios, revistas y hojas volantes, limitándose a señalar, en general, que su "influencia no por más callada deja de ser más profunda" (12). Lo mismo ocurre en la historiografía eclesiástica chilena, estancándose en la constatación de que la prensa católica nace como herramienta de combate contra la prensa irreligiosa o neutra y mencionando a los ejemplos emblemáticos de periodismo católico (13).

Sorprende la escasez de investigaciones sobre todo porque la prensa ha sido señalada como uno de los elementos fundamentales de la formación de la opinión pública, factor característico de la sociedad moderna (14). Sociedad que tiene sus pilares en la pluralidad de opiniones, en el debate y la consulta y en la autonomía

Lida, a quien tenemos mucho más presente y con quien compartimos algunos planteamientos generales. Por lo pronto, al parecer iniciamos nuestro estudio por la misma idea: resaltar que la prensa católica no se agota en su dimensión política e ideológica. Sin embargo, aquí no se propone que la prensa católica actúe como bisagra entre los laicos y la autoridad eclesiástica con todos los alcances que propone la investigadora argentina.

(7) Sergio Villalobos y otros, Historia de Chile, "Expansión y Crisis Nacional: 1861-1924", Santiago, Editorial Universitaria, 1989, p. 666.

(8) Ver, por ejemplo, Julio Heise, Historia de Chile. El Período Parlamentario, Santiago, Andrés Bello, 1974

(9) Raúl Silva Castro, Prensa y Periodismo en Chile: 1812-1956, Santiago, Universidad de Chile, 1956.

(10) Carlos Ossandón y Eduardo Santa Cruz, Entre las Alas y el Plomo. La Gestación de la prensa moderna en Chile, Santiago, LOM-DIBAM, 2001, p. 114.

(11) Sergio Grez, De la "Regeneración del Pueblo" a la Huelga General. Génesis y evolución histórica del movimiento popular en Chile (1810-1890), Santiago, DIBAM-RIL, 1997, p. 536. El autor no hace otros análisis y solo los menciona en una nota al pie.

(12) Ludwig Hertling, Historia de la Iglesia. Barcelona, Biblioteca Herder, 1989, p. 477.

(13) Ver, por ejemplo, Carlos Silva Cotapos, Historia Eclesiástica de Chile, Santiago de Chile, Imprenta de San José, 1925.

(14) Ver Benedict Anderson, Comunidades Imaginadas, México, Fondo de Cultura Económica, 1993. François-Xavier Guerra, Modernidad e Independencias, Fondo de Cultura Económica, 1992 
del sujeto individual. Sociedad moderna que establece un nuevo vínculo con la autoridad y con las normas en distintos tiempos y acorde al ritmo de cada conjunto humano. Es eso lo que queremos decir cuando afirmamos que el catolicismo, con la prensa en este caso, aceptó un nuevo plano y que incluso lo promovió. El mundo liberal llevaba impreso en su proyecto la expansión de la cultura escrita y fue el que más se empeñó en ese objeto, en contraste con el catolicismo que se interesó en su expansión cuando comprendió las ventajas de este medio para la difusión de sus ideas (15). Pero incluso tras percibir las ventajas de este medio, en Chile se acomodó tambaleantemente, y ello solo ocurriría a partir de la segunda mitad del siglo diecinueve, cuando el debate por la exclusividad religiosa le hizo imperioso entrar en un área poco transitada por sus huestes. Ante el embate liberal, el rol fundamental lo tendría la prensa (16). El catolicismo levantaría una cruzada en todos los ámbitos para ganar la opinión en todas las esferas sociales. Se fundaron diarios que compatibilizaban la religión con los aspectos políticos, literarios y comerciales. También periódicos "para el pueblo". El criterio de "la mayoría", "de la opinión general" o de la "opinión popular", cobraba importancia para los gestores. Recordemos, además, que en 1874 la ley electoral decretó el sufragio universal masculino, que permitía a "personas de cualquier clase y condición" la posibilidad de emitir su voto. En este punto es pertinente y necesario mencionar que, como sostiene Samuel Valenzuela, si bien el Partido Radical estuvo a favor de la reforma electoral, lo hizo de la mano del Partido Conservador, pues aunque el fin era distinto, bien podían, al menos, valerse del mismo recurso que habilitaban (17).

El sentimiento de pérdida de autoridad percibido por las cúpulas eclesiales debía ser contrastado con la autoridad que otorgaba el hecho concreto de que la religión católica fuera la religión del pueblo. Ese era el mensaje para quienes "atacaban" a "la" religión, o al menos, la religión verdadera. Esa era la meta, el objetivo. La jerarquía y laicos activos consideraban que el pueblo (18) era por "naturaleza" de carácter religioso. Debía, ahora, ser sinceramente católico. Para ello era necesario construir su religiosidad de otro modo: se pretendía incorporarlo a una ortodoxia y obediencia nuevas.

Pero no fue solo eso. Al menos tres alcances que se escapaban de sus manos se pueden vincular a su actuar.

Promover la prensa católica era reconocer, más o menos conscientemente, que se estaba en una nueva sociedad. Sus promotores aceptaron las reglas de un universo plural, o bien, en vías de su consolidación, y su sola presencia ayudó al fortalecimiento de la esfera pública (19), además del forjamiento del catolicismo como

(15) Sol Serrano e Iván Jaksic, "El poder de las palabras" en Historia, No 33, 2000, pp. 417-434.

(16) Sol Serrano, Vírgenes Viajeras. Diarios de religiosas francesas en su ruta a Chile, Santiago, Ediciones UC, 2000.

(17) Ver Samuel Valenzuela, "Hacia la formación de instituciones democráticas: prácticas electorales en Chile durante el siglo XIX” en Estudios Públicos, N 66, Santiago, 1997, p. 215-257.

(18) El pueblo es considerado de un modo tan amplio que encontramos en él al artesano, al labrador, al peón, a la niña de escuela, a la mujer del obrero y a la "mujer pública". Es el pueblo entendido en su acepción sociológica.

(19) Ver el problema de la inserción del catolicismo en este nuevo contexto en Sol Serrano, "La definición de lo público en un Estado católico. El caso chileno, 1810-1885" en Estudios Públicos, No 76 (primavera 1999), pp. 211-232. También en Serrano y Jaksic, El poder de las palabras. 
gestor de una opinión y una postura frente al mundo. Como una más, entre otras y con otras. Y el catolicismo hablando desde un lugar muy distinto del que lo había hecho antes. Ya no bastaba, por un lado, el púlpito y las prédicas. Por otro, el catolicismo hablaba desde el reconocimiento de una sociedad católica que vivía su religiosidad no del modo ortodoxo que se quisiera. Es decir, a la vez que reconoce que el pueblo era naturalmente religioso, este debe ser reformado en la forma de serlo. Hablaba desde la nostalgia de haber sido la religión de Estado y de querer mantener esa condición, considerada bajo un peligro máximo. El catolicismo, al entrar en este plano, acepta y contribuye a presentarse al mundo como "una alternativa" de sociedad, sin dejar de creer que es la religión verdadera, sin dejar aún su doctrina tridentina atrás, pero ahora no estaba en sus manos la asimilación de "chileno" con "católico" ni de "sociedad" con "sociedad católica". Si quería que eso fuese así, ahora debía ir a las conciencias y ganárselas entrando en debate con otras ideas y posturas.

En un segundo plano, si bien es cierto que la prensa se convertía en un medio para que la sociedad católica siguiera siendo tal, también lo es que su propuesta le abría al pueblo la puerta de entrada a un nuevo mundo. Se incorporó al pueblo a un espacio impensado, al ámbito de la esfera pública, tarde para otros actores, pero novedoso si lo pensamos desde el catolicismo. No decimos que se promovieran valores distintos de los posibles. El pueblo debía seguir siendo pueblo, no cambiar de estado, pero la relación sería distinta, el pueblo dejaba de ser parte del "conjunto de los seres humanos" para poder pasar a constituirse, incipientemente, en miembro de la sociedad civil universal (20). La unidad ilusoria de "pueblo" (el tercer estado todavía vigente) comenzaría a fragmentarse y sus miembros considerados como ciudadanos, partes y forjadores de la esfera pública. No sería solo la masa naturalmente religiosa, sino que podría ser, de manera ortodoxa, un sincero católico, un bastión necesario y opinante, defensor de las posturas eclesiales. Se inauguraba un nuevo rol para el pueblo y se lo situaba en nuevo lugar. Pasaba a ser el contenedor de la fe en la sociedad. Se le abrían los oídos también y se debería proceder a convencerlo.

Finalmente, como derivación de una perspectiva propuesta por David Brading (21), queremos sugerir que la "militancia", actitud de contraste del catolicismo con sus detractores, efecto de la laicización de la sociedad, generó de por sí la definición del catolicismo como un campo diferenciado. Pensamos que la prensa católica, por

(20) Ver Roger Chartier, Espacio público, crítica y desacralización en el siglo XVIII. Los orígenes culturales de la revolución francesa, Barcelona, Gedisa, 2003.

(21) David Brading en "Clemente de Jesús Munguía: Intransigencia ultramontana y la reforma mexicana" postula que la separación Iglesia y Estado fue inevitable no solo por causa de los liberales, que según él, buscaron apartar al clero de la esfera pública, sino también porque el clero buscó liberarse de toda intervención estatal sobre los asuntos de la Iglesia. Munguía, el Obispo ultramontano, habría sido autor de la separación tanto como Melchor Ocampo o Benito Juárez. Ahora bien, separación de la Iglesia y Estado no implicó marginación de la esfera pública si no restringimos este concepto a lo meramente estatal. Ver el artículo en M. Ramos Medina (comp.), Historia de la Iglesia en el Siglo XIX, México, Condumex, 1998, pp. 13-45. Como derivación de ese giro de apreciación, nosotros indicamos que la aceptación de las actividades como "católicas" provoca también la definición del catolicismo como una entidad diferenciada de la sociedad. 
su propia presencia y actividad, en cuanto delimita y forja una opinión, define, a su vez, el campo de acción que le compete y el grupo de personas al que convoca (22).

Este artículo tiene por objetivos comenzar a indagar en los orígenes de la prensa católica, que se remiten al siglo XIX. Si bien damos una orientación interpretativa de la prensa católica, el interés consiste en destacar el rol de la prensa católica destinada al pueblo como un medio por el cual el catolicismo comenzó y ayudó a pensar "el pueblo" en "ciudadanos" (23). Profundizaremos en un caso: El Mensajero del Pueblo, semanario católico publicado entre 1870 y 1886. Con él podemos concluir que existió en las cúpulas eclesiales un afán pedagógico, reformador y moralizador, pues si bien al pueblo se lo consideró bastión salvador de la sociedad, no podía seguir siendo el mismo pueblo. Esta pedagogía, que transita por el ámbito de la moral, las costumbres y la uniformización religiosa, consideró también el desarrollo de una conciencia cívica. El pueblo, para ser un sincero representante del catolicismo, debía ser virtuoso. La prensa, desde la jerarquía, se utilizó como un medio instructivo para lograr uniformar al pueblo en los nuevos requerimientos del catolicismo de fines del siglo XIX. El nuevo escenario que se configuró necesitó de estrategias nuevas y una de ellas fue el recurso al elemento mayoritario de la sociedad. Esa estrategia significaría, queremos sugerir, un lugar nuevo para el pueblo y en un ámbito más general, un factor que incidiría en la diferenciación del catolicismo del resto de los diferentes elementos de la sociedad.

\section{EL ECO DE LAS PRÉDICAS. LA EXTENSIÓN DEL PÚLPITO EN LAS HOJAS IMPRESAS}

"La palabra impresa derramada con profusión extiende indudablemente su voz mucho más allá de donde pueden llegar las instrucciones de un celoso pastor o los consejos orales de las personas dedicadas a moralizar al pueblo" (24).

Como "poderoso auxiliar de la palabra del sacerdote" (25) se definía a La Semana Religiosa, publicación católica que aparecía en Valparaíso en 1877. Tiempo

(22) Tal como lo han destacado con fuerza los trabajos de Roberto Di Stefano, en el periodo colonial existe una "poliarquía" de las distintas Órdenes religiosas. Esto significa que las Órdenes tenían, en la práctica, autonomía, pudiendo aplicar cada uno sus propios decretos normativos. Es en ese sentido que hablar de "Iglesia" en el periodo colonial carece de pertinencia, pues no existía una Institución Eclesiástica que se distinguiera claramente de la sociedad y que aglutinara a todos los cuerpos bajo una jerarquía. Será solo con el proceso de construcción del Estado Nacional cuando la "Iglesia" comenzará a institucionalizarse según el concepto actual. Si bien las conclusiones del autor se remiten al caso argentino el análisis tiene aplicación en Chile en este sentido. Ver especialmente "De la cristiandad colonial a la Iglesia nacional. Perspectivas de investigación en historia religiosa de los siglos XVIII y XIX”, Andes. Antropología e Historia, Número 11 (2000), pp. 83-113 y, por sobre todo, El púlpito y la plaza. Clero, sociedad y política de la monarquía católica a la república rosista, Buenos Aires, Siglo XXI, 2004.

(23) No hablamos aquí del incentivo directo de un razonamiento crítico y del desarrollo de una conciencia individual y autónoma, pues se trataba de un medio de movilización y de inculcación de una forma de sociedad, como lo eran también los periódicos de las otras tendencias. Es esta pluralidad la que permitía el contraste y el discernimiento.

(24) La Revista Católica, "Remedio del mal", 16 de marzo de 1867.

(25) El Mensajero del Pueblo, 10 de noviembre de 1877. 
antes, cuando El Mensajero salía a la luz, fue descrito como fruto del interés de los eclesiásticos que "día a día hacen escuchar su voz a través de la cátedra de los templos y que hoy quieren dar mayor alcance a sus trabajos evangélicos por medio de la prensa" (26). Por su parte, las palabras que inauguraban el primer número de El Chileno aclaraban esperanzadas que "[nuestro] concurso no debe medirse por el tamaño del papel, sino por la vasta circulación que esperamos alcanzar" (27). Palabras concentradas en 1867 y 1883 que difieren sustancialmente de las proclamadas en décadas previas, cuando la crítica a los periódicos impíos era la constante que se hacía sentir. ¿Por qué se produjo este cambio?, ¿qué cambió en la sociedad?

\section{Las exigencias de los tiempos}

La voz que se hacía escuchar día a día no era suficiente. Los conflictos político-religiosos enmarcados en el proceso de laicización del Estado como parte de la secularización ya habían comenzado a instalarse a mediados del siglo XIX chileno. Los tiempos habían cambiado. Los signos de los tiempos, vislumbrados de forma tardía, se transformaron en imperiosas exigencias. La proliferación de periódicos considerados neutros o adversos a la religión, el proceso incipiente de cambio de sectores sociales que maquinalmente se englobaban bajo la categoría de "pueblo", las deficiencias del alcance de una prédica, la necesidad de incorporar "al pueblo" a una ortodoxia novedosa como imperiosa necesidad de los tiempos contemporáneos y el desamparo religioso en que se encontraban vastos sectores de las diócesis llamaban a ocupar nuevas herramientas. Era necesario también para los mismos curas. Uniformarlos a ellos en la doctrina, que poco conocían, era un interés no menos relevante.

Chile incrementó año a año la cantidad de publicaciones periódicas a partir de la llegada de la primera imprenta en el gobierno de José Miguel Carrera. Tal como han señalado diferentes investigaciones, la prensa desplegó un papel de relevancia primordial en la gestación de las independencias americanas (28). Idea matizada al indicar que la prensa habría sido resultado de las independencias, más que un elemento generador de las revoluciones (29), pero no se ha puesto en duda el punto fundamental: su preeminencia sin parangones dentro del horizonte programático de las autoridades que tenían a su cargo la construcción de las repúblicas (30). De

(26) La Estrella de Chile, reseña de El Mensajero del Pueblo en "Revista Bibliográfica", 3 de julio de 1870 .

(27) El Chileno, editorial, 16 de diciembre de 1883.

(28) Especialmente François-Xavier Guerra, Modernidad e Independencias, Fondo de Cultura Económica, 1992.

(29) Rebecca Earle, "El papel de la imprenta en las guerras de Independencia hispanoamericana" en Entre Tintas y Plumas, pp. 19-43. Casos distintos del mexicano, por cierto incluido el de Chile, permiten a la autora probar su tesis. Sin embargo, el cambio de mentalidad en los independentistas ya estaba hecho: no por nada una de las primeras medidas es traer la imprenta.

(30) Si bien estudios como el realizado por Jorge Myers exigen la reinterpretación de la tesis que señala una importancia fundamental de la "print culture" en el desarrollo del Estado-Nación debido a que en Latinoamérica el contexto social es de un alto analfabetismo y de un espacio público reducido, estos no rompen con el hecho concreto de la difusión creciente que las empresas periodísticas tuvieron en el siglo XIX. Tampoco lo hacen respecto a la importancia asignada 
hecho, para el período entre 1812 a 1827 se tenía un registro de aproximadamente 80 periódicos (31). Entre 1828 y 1851 la cifra ascendía a 152 nuevas publicaciones. Mayoritariamente fueron "panfletos políticos", con gran relevancia en las coyunturas políticas de la época, pero se pensó también en lograr una mayor estabilidad para las prácticas periodísticas en función de su utilidad social (32). Las cifras, más que hablar de las magnitudes del público lector, lo hacen respecto del proceso de formación de la esfera pública chilena y del creciente interés por la difusión de las ideas, o dicho de otra forma, de la lucha por el predominio de la opinión: basta decir que la mayoría de las publicaciones del siglo cabe bajo el sello de una prensa ideológica o doctrinaria más que al de una empresa de carácter informativo o noticioso (33).

La prensa, además, era uno de los medios para la concreción de la expansión de la cultura escrita a los diferentes componentes de la sociedad. Esta expansión era la sangre del mundo liberal porque en el corazón de su proyecto estaba la formación de ciudadanos, base para la construcción de una república. La escritura permitía el vínculo entre individuos libres, formadores de la nación moderna. No fue así en la línea de la Iglesia. Esta se preocupó poco por el desarrollo de la educación primaria en la primera mitad del siglo XIX y pobre fue también su interés por la expansión de la cultura escrita, encarada más bien con temor (34) en el mismo momento que la administración estatal temía lo contrario: faltaban escuelas y solo un $30 \%$ de la población apta se beneficiaba de la instrucción primaria, aunque las cifras de los que saben leer y de los que escriben y leen habían aumentado en términos absolutos. Si en 1854 leían uno de cada 4,6 hombres y una de cada 8,3 mujeres, en 1865 lo hicieron uno de cada 3,9 hombres y una de cada 5,9 mujeres (35). El incremento de

por los mismos actores que, aunque hayan formado parte de un espacio público reducido, fueron los que tuvieron a su cargo la expansión de la prensa y que no tenían solo motivaciones meramente circunstanciales sino también educativas. Ver Jorge Myers, "Identidades porteñas. El discurso ilustrado en torno a la nación y el rol de la prensa: El Argos de Buenos Aires, 1821-1825", en Paula Alonso (comp.), Construcciones Impresas, Buenos Aires, 2004.

(31) Iván Jaksic, "Sarmiento y la Prensa Chilena del Siglo XIX" en Historia, N 26, Santiago, Instituto de Historia UC, 1991-1992.

(32) Jaksic, "Sarmiento y la Prensa". Las cifras para el período 1828-1851 se han obtenido a partir de los porcentajes calculados por Jaksic.

(33) Ver el estudio de Raúl Silva Castro, Prensa y Periodismo en Chile, 1812-1956, Santiago, Universidad de Chile, 1958. Recientes investigaciones dan cuenta de un progresivo cambio de esta condición de la prensa, la que habría ido incorporando cada vez más las características de periódicos "comerciales y noticiosos" más que ideológicos. Se ha insistido mucho en este aspecto, sobre todo, por las investigaciones que establecen una mirada desde el proceso de modernización de la actividad periodística, donde los periódicos decimonónicos adquieren un carácter de obsoletos en relación a las prácticas periodísticas "objetivas" y no ideológicas. Sin embargo, es precisamente ese "pecado" el que generó la importancia de la actividad y el reino de la opinión. Tenemos presente el análisis de Carolina Cherniavsky, El Ferrocarril de Santiago. El "cuerpo" de un diario moderno, Santiago, CIMAS Universidad de los Andes, 2004; y el libro ya citado de Eduardo Santa Cruz y Carlos Ossandón. Cabe destacar que la jerarquía diocesana chilena en ocasiones vio en los periódicos "neutros" a un enemigo mucho mayor que a los francamente irreligiosos. El periódico neutro tenía el efecto de mezclar en unas mismas páginas información para moros y cristianos, lo que iba en contra del ideal del catolicismo de fines del siglo. Un periódico neutro aumentaba el peligro del indiferentismo y de la pasividad de los católicos.

(34) Serrano y Jaksic, El poder de las palabras.

(35) Anuario Estadístico de la República de Chile, 1875-1876, "El Censo de 1875", Santiago de Chile, Imprenta Nacional, 1877, pp. 112-121. Ver también el correspondiente a los años 1876-1877, "Instrucción Pública", pp. 414-415. 
la alfabetización abría desafíos inéditos para la Iglesia. Además, como lúcidamente ha indicado Patricio Bernedo, la prensa es un fenómeno fundamentalmente urbano por lo que los análisis respecto de los niveles de alfabetización deben concordar con estas áreas. En ese sentido la recepción podía tener mucha mayor relevancia, aunque la jerarquía también haya pensado la prensa para las zonas rurales (36).

El catolicismo, acostumbrado a un público letrado fijo y pequeño, su pastoral orientado al pueblo se desarrolló más bien en el ámbito oral, mediante las prédicas de los curas párrocos. El catolicismo atiende a la importancia de la lectura y la escritura en la medida que "aumenta" su feligresía capaz de captar los escritos o "papeluchos" que atentaban contra su exclusivismo religioso. Es en ese momento cuando le resultó imperativo instruir a través de las lecturas, entre ellas, lecturas a través de la prensa, convirtiéndola en una extensión o eco de las prédicas.

Junto a ello, en la intimidad misma de la administración eclesiástica chilena, se palpaba una realidad ineludible: fuera del núcleo citadino no había capacidad para la atención pastoral regular de sus fieles. Si bien la línea de reactivación parroquial fue promovida con fuerza con Manuel Vicuña y Rafael Valentín Valdivieso, tuvo resultados pobres, sobre todo en cuanto al contacto de los párrocos con el total de su feligresía. Esto fue así en el Obispado de Santiago. En los tres restantes la situación no pudo ser en ningún caso mejor. A cada circunscripción parroquial le correspondía un número muy alto de fieles y distribuidos en forma dispersa (37). Además, como señala Javier González Echenique, los párrocos se enteraron recién hacia 1859 que les correspondía realizar catequesis junto a los encargos pastorales ordinarios. En 1873-1875 la parroquia de Cáhuil era evaluada con deficiencia en este sentido por los recuerdos del Cardenal José María Caro. La “imposibilidad física” de prestar los auxilios religiosos a los fieles se atenuaba con la práctica de misiones, pero estas se realizaban una vez al año con el objeto de que se pudiese cumplir con el precepto pascual. En la época de Valdivieso la situación se fortaleció cuantitativamente en relación a los lugares visitados, pero no en su reiteración en el mismo año (38). La reactivación respondía, según Misael Camus, al interés especial de los Obispos por tener un estilo de pastoral parroquial, cuidando con énfasis que no se entregaran las parroquias a órdenes religiosas, a pesar de algunas contadas excepciones (39), punto muy propio del pensamiento teológico ligado al catolicismo ilustrado (40). Ahora, si bien las parroquias aumentaron de 136 en 1869 a 160 en 1880 y 172 en 1889 , Camus llama a contrastar las cifras con las de crecimiento demográfico del período y con el estado material de las mismas parroquias. En su mayoría, materialmente pobres,

(36) Bernedo, "Usando las armas del adversario", p. 103.

(37) En 1870 el Obispado de Concepción tenía 14.250 personas en promedio por parroquia; el de Ancud, 8.723; el de La Serena contaba con 13.322 y el de Santiago con 14.160. Ver Anuario Estadístico de la República de Chile, 1870-1871, Santiago, Imprenta Nacional, 1872.

(38) Javier González Echenique, "Las Parroquias y la Vida Religiosa Campesina de la Zona Central. Episcopado de Rafael Valentín Valdivieso (1845-1878)" en Vida Rural en Chile durante el Siglo XIX, Santiago, Academia Chilena de la Historia, 2001, pp. 281-329.

(39) Misael Camus, La Iglesia en Chile, 1840-1924. Incubación y desarrollo de un nuevo modelo eclesial, Antofagasta, Universidad Católica del Norte, 2000.

(40) Mario Góngora, "Aspectos de la Ilustración Católica en el pensamiento y la vida eclesiástica chilena (1770-1814)", Estudios de historia de las ideas e historia social, Valparaíso, Ediciones Universitarias, 1980 . 
mantenían en relativas buenas condiciones solo la parte administrativa, lo que se explica por la función de "registro civil" que cumplían antes de las leyes laicas. Con este panorama, Camus afirma que se debe replantear la hipótesis de que la escasa atención pastoral obedece a la caída de las vocaciones sacerdotales, pues aunque hubiesen crecido al mismo ritmo habría sido imposible cubrir las necesidades de la creciente población. El autor no se concentra en un tema trascendental para los nuevos tiempos: no existían los medios ordinarios de asistencia a la feligresía en todos los sectores. Estos debían quedarse con la prédica de la misa, pero ello también es relativo. ¿Se asistía regularmente a misa? ¿Cuál era la recepción de ella? ¿Quiénes y cuántos no contaban con recursos religiosos? A la espera de estudios que amplíen este conocimiento, solo podemos decir que fuera de la iglesia parroquial ni siquiera se podía contar con la misa dominical de forma regular. Las misiones recorrían los lugares más apartados, una vez al año o incluso con menor regularidad (41). En este marco se entienden las palabras de los sacerdotes que promovían la prensa y que las veían como un "poderoso auxiliar" de la actividad parroquial. La idea de que un periódico se traslada con mayor facilidad y de que podía permanecer con el fiel está presente en los gestores de prensa junto con el interés creciente en aumentar la "circulación" para poder decir de la prensa católica lo atribuido a los folletos protestantes: "penetran donde se quiera". Si bien la difusión de la prensa es un fenómeno especialmente urbano, es interesante constatar que hubo sectores del clero que pensaron en su expansión a los distintos pueblos y villas.

La diferente impregnación del catolicismo formaba distintos escenarios según los rincones del país, pero Santiago, la ciudad capital, concentró cambios en forma intensa que clamaban por una readecuación. Esta, en pocos años había pasado de ser "la ciudad de Martín Rivas" a la de "Benjamín Vicuña Mackenna" (42). Tan solo en un par de décadas, el crecimiento demográfico, la diversificación de las funciones y la evolución de las formas de vida transformaron la capital. La ciudad se hacía parte, con sorpresa, del desarrollo de una economía moderna, donde los sectores populares se perfilaron como trabajadores, como "los obreros" (43). Santiago se hizo cargo de la llegada de unos 60 mil nuevos habitantes, y con ellos, de la demanda por habitaciones y servicios que no tenía. La respuesta fue de emergencia. Los ranchos y cuartos se multiplicaron. Más que nunca la falta de agua potable y de alcantarillas urgieron la mente de las autoridades. Las pestes, concentradas entre fines de los años 60 y comienzos de los 70 , pintaron de dramatismo el cuadro que ya era caótico. Concepción y Valparaíso, como segundas ciudades, también vivían el proceso, pero en esta última se agregaba con más fuerza dos enemigos manifiestos del catolicismo. Los protestantes desarrollaron una vigorosa actividad a partir de la llegada del misionero David Trum-

(41) La comunicación del cura con la feligresía que se encontraba dispersa y el escaso tiempo dedicado a ella eran problemas generalizados en el país. Ver González, "Las parroquias y la vida religiosa".

(42) Luis Alberto Romero, ¿Qué hacer con los Pobres? Elites y sectores populares en Santiago de Chile, 1840-1895, Buenos Aires, Editorial Sudamericana, 1997.

(43) Para la revisión de esta idea en profundidad ver Sergio Grez, De la "regeneración del pueblo" a la Huelga General, Génesis y evolución histórica del movimiento popular en Chile (1810-1890), Santiago, DIBAM, 1997. 
bull, quien junto con intentar edificar sobre rocas el ejercicio de su culto, fundó un hogar para niños desamparados y difundió miles de volantes entre la sociedad porteña. Junto a ello, se empeñaron por impartir educación a niños de habla inglesa de escasos recursos, lo que lograron con éxito. De la misma manera, los masones levantaron el resquemor del catolicismo. Una de sus materias se ciñó a la difusión de la instrucción a los pobres, para lo que fundaron una Sociedad de Instrucción Primaria. Entre 1872 y 1873 se fundaría la escuela "Blas Cuevas" y la "Escuela Sarmiento", las que serían ardorosamente combatidas por los católicos (44).

Los cambios, visiblemente establecidos ya en la segunda mitad del siglo XIX, parecieron reclamar la utilización de armas nuevas por parte del catolicismo para llevar a cabo su proyecto, tanto en el mundo de las ciudades principales como en las más recónditas.

\section{De un dique tradicional a un dique moderno}

Los miembros de la jerarquía de la Iglesia expresados a través de La Revista Católica notaban con reticencia la expansión de la prensa y la educación primaria en orden a una consideración: estas eran buenas si servían como vehículo de difusión de las "buenas ideas", en la perspectiva de un Estado oficialmente católico. La primera estrategia que el catolicismo -jerarquía y laicos- encontró a mano fue la difusión de una cantidad mayor de escritos de orden religioso, en la línea de literatura piadosa y material devocional. De hecho, la tendencia de impresión aumenta desde la segunda mitad del siglo: si desde 1812 a 1850 se pueden contar 537 impresos, a partir de 1851 hasta 1875 el total asciende a 1.238, más del doble de impresos para un periodo que comprende 14 años menos (45). Sin embargo, hacia 1860 se podía distinguir que ahí no estaba únicamente la solución. La prensa periódica se tomó como otra alternativa, aunque de modo tambaleante y "lento" como fue la tónica en la expansión escrita en general (46).

Las posturas en torno a la prensa fueron ambivalentes y permanecieron así, incluso cuando el conflicto político-religioso había cobrado resonancia pública. Si bien en 1843 se había avanzado un paso al iniciarse el camino de La Revista Católi$c a$, está probado que su alcance era restringido a las cúpulas del clero (47). En palabras de Crescente Errázuriz era un "periódico semanal de escasísima circulación, llegaba a muy pocas manos, fuera de la de los eclesiásticos" (48). Años después señalaba que "llevaba La Revista Católica una vida lánguida, que casi no merecía el nombre de vida. De ordinario, ni los que cuidábamos de su publicación,

(44) René Millar, “Aspectos de la Religiosidad Porteña. Valparaíso, 1830-1930”, Historia, N³3, 2000, pp. 297-368.

(45) Cifras calculadas a partir del estudio de Sol Serrano, "La privatización del culto y la piedad católicas" en Historia de la vida privada en Chile. El Chile moderno, de 1840 a 1925, Santiago, Aguilar, 2006. Si bien solo las cifras de publicación no son suficientes para hablar de demanda, si se puede concluir que el catolicismo buscó la proliferación de escritos religiosos.

(46) Serrano y Jaksic, "El poder de las palabras".

(47) Serrano y Jaksic, "El poder de las palabras". Por lo demás, los autores señalan que no se encontraba en el inventario de ninguna parroquia.

(48) Crescente Errázuriz, Algo de lo que he visto, p. 110 
leíamos lo que allí salía: ¿Qué serían los demás? Sólo en ocasiones, cuando algún asunto tocaba de lleno con la religión, servía de órgano a la autoridad eclesiástica, para defender los intereses católicos y dar la voz de alarma a los fieles. Necesitábase, por tanto, de ella, aunque en tiempos normales arrastrase una existencia casi inútil" (49).

Desde sus páginas podemos afirmar que la autoridad eclesiástica ocupó bastante tiempo en criticar los escritos "irreligiosos" que, según sus miembros, se vertían cada vez más seguido en El Mercurio de Valparaíso y en El Ferrocarril (50). La prensa en sí misma y como herramienta, no era criticada. Más aún, era definida como un "gran descubrimiento de los tiempos modernos, sin duda un gran poder civilizador que ha impulsado a la humanidad por la vía del progreso". La prensa había sido el descubrimiento que cambió la forma de civilizar. Ya no era necesario el derramamiento de sangre si se utilizaba este "elemento divino" (51). Sin embargo, junto a la alabanza, coexistía la crítica a la utilización que hacían los impíos de él. El diagnóstico era claro. La prensa periódica se encuentra "llena de indiferentismo religioso", de "inmundos artículos" y esto porque "los impíos se han apoderado de la prensa" (52). Se lamenta "la suerte de la prensa" exclamando: "oh!, por el honor y sensatez de Chile protestamos contra la conducta de la prensa que derrama el más funesto veneno, en vez de ser el vehículo de las buenas ideas" (53). La crítica se engloba dentro del concepto de las "malas lecturas". Malas porque introducían al "joven inexperto corazón en sociedad con hombres viciosos y perdidos". No obstante, el punto se hacía más ardoroso cuando se trataba de periódicos irreligiosos o inmorales pues su variedad los hacía aptos "a todo tipo de inteligencias" y su mayor difusión hacía que se "redoblaran los peligros" (54). Larraín Gandarillas lo recordaba con firmeza: estaban prohibidas todas las malas lecturas, que junto a los libros incluía también a "todas las hojas, aún manuscritas, y todos los escritos en que de cualquier modo se ataca a Dios, a los Santos, a los sacramentos, a la Iglesia Católica, su culto o a la Sede Apostólica" (55).

(49) Ibid., p. 181-189.

(50) Ver, por ejemplo, cuando estos periódicos publicaron a través de sus páginas el artículo "Despierta Italia", una "exposición radical y revolucionaria" en las palabras de La Revista Católica, la que se apura en censurar preguntando "si acaso El Ferrocarril y El Mercurio se proponen levantar la bandera roja y socialista y si así la prensa aboga por los intereses de la sociedad”. En La Revista

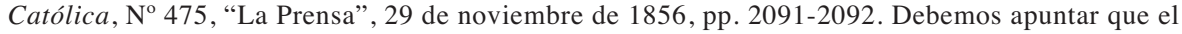
peligro "rojo" era imaginado para Chile en las mentes de la jerarquía, sobre todo después del establecimiento de la Sociedad de la Igualdad, a la que atribuían todos los postulados de la "revolución francesa socialista de 1848" y de ahí el rechazo tan férreo de los Boletines del Espíritu, publicados por Francisco Bilbao.

(51) La Revista Católica, No 458, "La prensa periódica y los intereses religiosos", 1856, pp. 1646.

(52) La Revista Católica, No 235, "La Prensa de Copiapó", 14 de febrero de 1851, pp. 33-35.

(53) La Revista Católica, $\mathrm{N}^{\circ} 475$, "La Prensa".

(54) Joaquín Larraín Gandarillas, Edicto sobre las malas lecturas, Santiago, Imprenta del Correo, 1886.

(55) Larraín Gandarillas, Edicto sobre las malas lecturas. La misma idea ha dado a luz recientemente Patricio Bernedo, revisando especialmente el documento eclesiástico titulado Los periódicos irreligiosos ante la conciencia católica (Santiago, Imprenta del Correo, 1868). Ver Patricio Bernedo, "Usando las armas del adversario", pp. 104-105. Si bien en el presente artículo coincidimos en el análisis, es pertinente resaltar la ambivalencia en la aceptación del diagnóstico. Es decir, no queremos decir aquí que el catolicismo llevó a cabo una empresa periodística sistemática. Fue a todas luces fundamentalmente construida sobre la marcha y por ello mismo, la inestabilidad fue una de sus características. 
Los artículos en La Revista Católica juzgan crudamente la realidad en que ha caído la prensa para promover la acción de las plumas católicas. Crescente Errázuriz rememora que se juzgaba cuán prudente sería la aparición de un nuevo medio de prensa debido a lo inconveniente que podría resultar una nueva publicación. Basta mencionar que las suscripciones a El Mensajero del Pueblo cayeron cuando apareció El Estandarte Católico y que además su presencia fue la ausencia de La Revista Católica. Por su parte, cuando se empezó a publicar El Chileno, El Mensajero del Pueblo tuvo sus días contados. Los mismos suscriptores, benefactores y los mismos redactores, no daban alcance para más que un número limitado de publicaciones (56). No obstante ello, las ediciones católicas aumentan con el paso de los años. Tal como se puede desprender del cuadro 1, en el período 1812-1827 había 2 periódicos católicos y entre 1828 y 1851 hubo 4 nuevos (57). Entre 1851 y 1865 serían 5, mientras que en 1866 a 1891 se pueden contar 18 nuevos periódicos, lo que corresponde a un $62 \%$ del total de la prensa católica del siglo (58).

Sin embargo, al contrastarlas con el total de las publicaciones, es entendible que el ánimo de los gestores y promotores bordeara la preocupación. No podía ser de otra forma si en 1860 recién se tenía alguna noción de los objetivos de la "prensa religiosa". La realidad, entonces, "ya no puede disimularse", se indican los medios por los cuales esta nueva tarea "no ofrece mayores sacrificios" señalando que se pueden realizar algunas adaptaciones de las publicaciones de otros países "y ahorrar así muchas veces el trabajo de una composición original" (59).

Junto al énfasis en las críticas, las muchas cavilaciones, rencillas internas y dentro de los temores se unía la idea de que el escrito religioso, en lo dogmático y

(56) Un análisis acabado del cuerpo de redactores, benefactores y suscriptores de todas las publicaciones periódicas católicas ligadas a la jerarquía eclesiástica podría arrojar que tuvo entre sus filas a las mismas personas o familias, asunto que podemos afirmar solo hipotéticamente en base a las referencias que nos ha dado la investigación. Junto a ello, se podría afirmar que se trató de un círculo más bien reducido en el campo de los benefactores y suscriptores. Un ejemplo de ello, lo representa El Porvenir de las Familias, periódico que publicó la lista de suscriptores en El Ferrocarril, donde podemos con que una misma persona concentra un alto número de suscripciones, haciéndolo además por varios años.

(57) Debemos destacar que en este análisis estadístico estamos incluyendo los periódicos dependientes de la jerarquía y los laicos. Los periódicos anteriores a 1851, a excepción de La Revista Católica, corresponden a publicaciones esporádicas de órdenes religiosas.

(58) Estamos incluyendo aquí solo el material periódico y no libros, devocionarios u otra literatura de orden religioso. Creemos que el cambio está no tanto en el aumento del material religioso tradicional, sino en la entrada del escrito religioso en publicaciones diarias. Debemos advertir también que hemos excluido de la tabla las publicaciones aparecidas con motivo de la fusión liberal conservadora, aunque miembros de estas "empresas periodísticas" participaran después en los periódicos católicos dirigidos por el Arzobispado o bien por miembros del Partido Conservador. Se han excluido además las publicaciones exclusivamente parroquiales debido a la imprecisión de la información, a su corta duración y a la aparente excepcionalidad de su existencia. Fuente: Simon Collier, Ideas and Politics of Chilean Independence; Iván Jaksic, Sarmiento y la Prensa Chilena del Siglo XIX; Anuario de la Prensa en Chile; Raúl Silva Castro, Prensa y Periodismo en Chile; Carlos Silva Cotapos, Historia Eclesiástica de Chile; La Revista Católica; El Mensajero del Pueblo; Ramón Briseño.

(59) La Revista Católica, 16 de marzo de 1867. Temores y desánimos que eran justificados. Cabe señalar que tan solo en 1918 las visitas pastorales inquieren algún rasgo de preocupación por los escritos al incluir las preguntas ¿Qué periódicos se leen?, ¿qué ideas profesan?, ¿hay prensa católica? Misael Camus, Historia de la Iglesia en Chile. 
doctrinario, debía ser expuesto en grandes tratados. Aunque solo desde artículos publicados en La Revista Católica, es posible sostener que el escrito religioso, para algunos, no podía ser puesto en hojas periódicas. El dogma y la doctrina estaban revestidos para algunos miembros de la jerarquía de una sacralidad tal que no era posible sino ponerla en grandes libros. En 1867, un par de años después de la discusión de la ley interpretativa del artículo $5^{\circ}$ de la Constitución de 1833 , se evidenciaba el problema: ¿era posible que los principios de la religión se colocaran en "hojas de papel periódico"? Si bien el artículo posee como objetivo el incentivar la prensa católica, en él se puede ver de modo indirecto cuáles eran los motivos que generaban la pasividad. El autor argumenta que "católicos hay que no quisieran ver agitarse cuestión ninguna a ese respecto en el terreno de la prensa. Les desagrada altamente el oír la voz de la fe, clamando contra el error, siempre que esa voz se levanta en las columnas de un diario" (60). Interroga señalando que "si el mal se ostenta allí mismo, si el veneno se vierte por la prensa y por los diarios ¿por qué el pueblo fiel no puede ver allí también la luz de la verdad católica?" (61). Califica de "católicos asustadizos" a quienes no se percatan de que la forma de combatir el error ha cambiado. Continúa su argumento indicando que San Agustín, en estas circunstancias, no habría dudado en ocupar la prensa como medio para escribir sus tratados (62). Se quería evitar la relación con ideas políticas que desviaran la trascendencia de la religión, el alejamiento o errores de la interpretación doctrinal y las disputas entre las mismas publicaciones católicas. Ahora bien, "porque las necesidades religiosas del país crecen día a día y [porque] se propagan las ideas irreligiosas", era urgente oponer "diques para detener [su] desborde" (63).

El diagnóstico por sí solo no daba todas las respuestas. Se debía definir qué tipo de dique era el necesario. En 1862 Monseñor Rafael Valentín Valdivieso señalaba al Delegado Apostólico del Vaticano que, frente a la utilización de la libertad de imprenta en perjuicio de la religión, "no queda, pues, otro remedio contra tan perniciosos males, que los edictos pastorales, las publicaciones religiosas, las predicaciones, etc., y estos medios son los que se procuran poner en planta" (64). Doce años más tarde, aunque visibles un tiempo antes, las palabras son distintas y dan cuenta del cambio: "será vano empeño el querer poner un dique al desborde de la impiedad con solo los tratados fundamentales de las verdades que los enemigos de la religión acostumbran negar" (65). Presuntamente era Crescente Errázuriz quien apuntaba que ya no era el libro, sino los diarios los que satisfacían las necesidades de la generación presente, porque los diarios están al alcance de todos, porque se les puede adquirir por el interés del momento y porque es reducido el número de personas que buscan específicamente un alimento sano y nutritivo para su inteligencia en los libros.

La crítica a la libertad de prensa en el ámbito institucional, siguiendo a Roger Aubert, recién será dejada de lado por el pontificado de León XIII. Es él quien

(60) La Revista Católica, N 967, "El periodismo católico”, 13 de julio de 1867, pp. 496-497.

(61) Ibid.

(62) La Revista Católica, $\mathrm{N}^{\circ} 967$.

(63) La Revista Católica, N ${ }^{\circ}$ 458, "La prensa periódica y los intereses religiosos", p. 1646.

(64) Citado por Serrano-Jaksic, "El poder de las palabras".

(65) Ibid. 
insiste en que es preciso evitar las estériles discusiones teóricas sobre el régimen ideal y ponerse de acuerdo para usar con la mayor eficacia posible las instituciones liberales para promover las reivindicaciones católicas. En ese sentido, en vez de protestar contra la libertad de prensa, era preciso utilizarla (66). En Chile, como en la mayoría de los países europeos y americanos, se comenzó a trabajar un tiempo antes del incentivo pontificio, teniendo como hito a 1857 , fecha en que el conocido como "asunto del sacristán" exteriorizará uno de los tantos problemas que arrastraba la persistencia de la unidad entre Iglesia y Estado. Los periódicos católicos publicados entre este año y 1884, fecha que había visto ya la aprobación de las leyes laicas, alcanzan un porcentaje de 41,3\% del total de todos los periódicos católicos del siglo. Quedaba atrás el combate con solo "pastorales", "predicaciones" y críticas.

Seguir la huella de las consecuencias del cambio resulta prácticamente imposible. Sin embargo, parece evidente, y así lo sintieron también los actores, que la prensa rompía con el esquema tradicional. El catolicismo, junto con ampliar su producción escrita también cambió la forma y diversificó el público al que difundían sus escritos. La literatura religiosa, junto con aumentar, se concentró en el material de tipo devocional, introduciendo un cambio fundamental en la experiencia religiosa: la piedad individual (67). Pues bien, si solo la introducción de los escritos incorporaban vetas inéditas en el catolicismo, ver qué tipo de escrito y cómo se difundían esos escritos no es de menos importancia (68). La entrada al campo de la prensa implicaba matizar la idea de que la doctrina religiosa debía ser expuesta solo en gruesos libros a modo de grandes tratados dogmáticos. El cambio de una estructura ancestral de prácticas explica la lentitud, confusión, desinterés y temor con la que se asumió la tarea (69). No se trataba de acabar con métodos tradicionales solo en el ámbito del pueblo, a quienes se les "predicaba", sino también de cambiar la mentalidad de la "cúpula letrada", acostumbrada a exposiciones "acabadas" de cada una de las materias. Con ello, el catolicismo, ocupó las mismas herramientas de los "impíos", el medio moderno por excelencia del siglo XIX, para la propagación de la fe. Ello ayudaría a fortalecer el asentamiento de un catolicismo más secular y social, en tanto entraban a preocuparse por las críticas vertidas a una religión centrada en prácticas del culto, además del inicio de un

(66) R. Aubert, Nueva Historia de la Iglesia. La Iglesia en el Mundo Moderno, Ediciones Cristiandad, Madrid, 1977, tomo V.

(67) Serrano, "La privatización del culto y la piedad católicas".

(68) Creemos que se puede aplicar las hipótesis de Roger Chartier que apuntan a la desacralización de la lectura mediante un proceso de cambio en las prácticas de lectura que se va denotando a través de diferentes signos. Lectores confrontados a textos más numerosos, la lectura íntima y solitaria, junto a textos menos durables y el aumento de los impresos efímeros como los periódicos, se ven empujados a una lectura más libre, desacralizada y, por cierto, más crítica. Ver Roger Chartier, Espacio público, crítica y desacralización en el siglo XVIII, Barcelona, Gedisa, 2003, especialmente pp. 104-106.

(69) Debemos recordar que el impreso en el período de Antiguo Régimen jamás pudo pensarse para opinar sobre asuntos de moral o de religión y es más, ninguno tenía que ver con la generación de discusión. Tenían carácter informativo y de "asistencia al público" y sus asuntos básicamente eran la inclusión de precios del abasto, el calendario de fiestas religiosas y anuncios de sentencias eclesiásticas y civiles. Ver Annick Lempérière, "República y publicidad a finales del Antiguo Régimen (Nueva España)" en François-Xavier Guerra y Annick Lempérière, Los espacios públicos en Iberoamérica. Ambigüedades y problemas, México, FCE, 2001, pp. 54-79. 
camino que, por esos años, rechazaban a todo nivel: la tolerancia y la afirmación de otra fe (70). El credo en las páginas de la prensa entraba al campo de la opinión pública, al terreno de lo opinable y de lo discutible. Existe un interés por establecer un dique al torrente de publicaciones irreligiosas, pero este dique cambió desde uno de carácter tradicional a uno moderno.

\section{"La valla que resiste"}

Los cambios que atentaban contra la exclusividad del catolicismo significaban, desde su perspectiva, una causa de destrucción del orden social. La prensa católica era, entonces, una obra de bien público. La libertad se quería "en el orden” y ese orden lo garantizaba una religión: la católica. La prensa católica aparecía, desde ahí, con el rol de procurar la prosperidad del país y la civilización (71). La preocupación se enfocó hacia diferentes ámbitos. Se pensó en utilizar la prensa para uniformar el criterio del clero, para que los fieles más letrados no perdieran su fe, como forma de tener opinión frente a la contingencia y defender así los principios católicos. También se pensó en "el pueblo". El pueblo proporcionaba esperanzas de contención, y por ello, se centró en él su atención y se le movilizó para que ejerciera fuerza en la opinión. El pueblo, el mismo que era religioso "por naturaleza", podía ser pervertido por la proliferación de los "folletos impíos" (72), pero también podía ser bastión contra doctrinas pertubadoras.

El interés por el pobre era una expresión de la caridad, pero además una respuesta, una reacción frente a los protestantes y otras corrientes de pensamiento que apelaban al pueblo y que los católicos enmarcaban bajo el signo del socialismo (73). La inquietud respecto al por qué formar al pueblo estuvo en las mentes de la autoridad eclesiástica, y la respuesta es clara: simplemente porque el pueblo era la valla que resistía el embate de los irreligiosos a la sociedad:

Cuando por todas partes se ven desarrollarse los gérmenes del mal y producir terribles estragos, cuando los enemigos del bien emplean todos sus bríos para minar los principios conservadores de la estabilidad social y religiosa, indudablemente el pueblo todavía sano, es la valla que resiste sus formidables ataques e impide un desborde completo de toda clase de desórdenes sobre la sociedad. Si una vez el pueblo se pierde, si falta su amor por lo santo y lo bueno, la hora de la ruina y de la desgracia para la república está muy cercana,

(70) Un ejemplo meramente ilustrativo de la concepción al respecto, lo reflejan las siguientes palabras: "en medio de la tolerancia, que cada día aumenta más en nuestro suelo, no vemos otro remedio eficaz a mal de tan funestas consecuencias -los folletos protestantes-, que oponer de nuestra parte toda la abundancia de bien que nos sea posible", La Revista Católica, "Remedio del mal", $\mathrm{N}^{\circ}$ 951, 16 de marzo de 1867, pp. 49-51.

(71) La Revista Católica, No 475 , "La Prensa".

(72) La Revista Católica, $\mathrm{N}^{\circ}$ 917, "Propaganda protestante", 10 de febrero de 1867. Aquí se rechaza categóricamente la difusión de los folletos protestantes exhortando a los párrocos a combatirlos mediante sus prédicas, lo que nos indica que todavía no se podía echar mano de un medio periodístico que tuviera un mayor alcance que las palabras del cura.

(73) Bernardino Llorca S. I., Ricardo García Villoslada S.I. y Francisco Javier Montalbán S. I., Historia de la Iglesia Católica. Edad Moderna (1648-1958), Madrid, BAC, 1958, tomo IV, p. 793. 
todos los demás elementos del bien no serán capaces de sostener el torrente devastador, ni de apagar el fuego prendido por la tea traicionera de los apóstoles del mal (74).

Fue, también, una estrategia respecto de la hegemonía del Estado liberal. Siguiendo a Sol Serrano, la caridad decimonónica católica para el caso de Chile, organizada e institucionalizada, está lejos de ser una "vieja práctica", y se constituye más bien en una práctica nueva, propia del complejo reciclaje católico ante la secularización del Estado (75). El florecimiento de este interés en un período en que "los pobres" eran reclamados por distintas fuerzas ideológicas pueden ser claramente atisbos de un "catolicismo social".

Ahora bien, la jerarquía eclesiástica percibía algo más concreto: el "pueblo religioso" no era "religioso" al compás de las nuevas exigencias, y no sabía, desde la jerarquía, qué era ser un "sincero católico". La valla resistidora, fuerte, capaz de salvar y contener la desgracia de la sociedad, no tenía la formación que ahora se imponía como necesaria. La prensa se ocupó como medio catequístico y pedagógico. Se seguía la línea de países europeos como Francia, Bélgica y Alemania que habían enfrentado las revoluciones de 1848 mediante el rechazo del "terror rojo". Fue este uno de los elementos que motivaron la preocupación por el pueblo, sobre todo al haberse introducido el sufragio universal, factor en el que se vio un elemento con el cual influir notablemente. El pueblo era quien se encargaría de mantener a Dios en las leyes, en las escuelas y en el hogar. En Chile, no habían ocurrido revoluciones con apelación masiva al pueblo, pero sí se había legislado a favor del sufragio universal masculino en 1874 (76). Junto a ello existía una disputa por la catolicidad del Estado. En ese contexto, que la católica fuese empíricamente la fe de la mayoría de los chilenos no era una cuestión de poca importancia. El catolicismo no quería dejar de ser la religión del Estado, pero ante el creciente cuestionamiento de esa unidad, tenía que abrir un vínculo legitimador de otra especie. El camino hacia una ruptura del lazo jurídico de la Iglesia con el Estado debía ser reforzado con el hecho de que el catolicismo fuera la religión del pueblo, y con ello, de la mayoría de la sociedad chilena. Ahora importaba el número. Con ello, también, se estaba inaugurando un nuevo rol para el pueblo. Si a la mujer se le asignó el papel de contenedora de la fe en la elite, el pueblo era el contenedor de la fe en la sociedad.

\section{EL MENSAJERO DEL PUEBLO: REFORMAR PARA CIVILIZAR}

El sábado 10 de junio de 1870 salió de las prensas un semanario de formato pequeño, más cercano a un devocionario que a un periódico: El Mensajero del Pueblo. Tres años antes se había discutido en La Revista Católica la pertinencia de unas hojas que atendieran a las necesidades y promoción de los principios católicos al pueblo. En el segundo número, la revista oficial de la jerarquía bendecía a la

(74) La Revista Católica, $\mathrm{N}^{\circ} 951$

(75) Sol Serrano, Vírgenes Viajeras.

(76) Samuel Valenzuela, "Hacia la formación de instituciones democráticas". 
publicación e indicaba claramente que se trataba de la materialización de su antigua idea: “¡Cuánta satisfacción hemos tenido al ver completamente realizada nuestra antigua idea! El Mensajero del Pueblo, cuyo primer número tenemos a la vista, viene a llenar un gran vacío, su misión es importantísima, y no dudamos que habrá encontrado la más favorable acogida en toda persona amante de la ilustración y del bien de la patria" (77). Las consideraciones de gozo no se hicieron esperar. "Centenares de personas se muestran ávidas de leer esas líneas impregnadas de caridad, sin mezcla de pasión" (78), eran las palabras felices de los editores diagnosticando la buena recepción del semanario. Otras analizaban los contenidos y satisfactoriamente concluían que "en cada uno de sus artículos esta publicación justifica su nombre" (79).

Con misión análoga a las instituciones de educación e instrucción que se estaban, a sus ojos, proliferando por las ciudades del país, se propusieron "la enseñanza social del pueblo". Esto era: hacer llegar a las clases más humildes el conocimiento de sus deberes, las nociones elementales del saber, los medios de mejorar su condición moral y social y arraigar las convicciones católicas (80). En su fundación estuvieron presentes Alejandro Larraín, Luis Campino y José Ignacio Víctor Eyzaguirre, todos presbíteros. Los tres sacerdotes tenían una trayectoria de desarrollo e interiorización de un pensamiento teológico vinculado al Catolicismo Ilustrado (81), concibiendo una religión que cooperara con la educación, la moralización del pueblo y la preocupación por los trabajadores agrícolas (82). Estos "remanentes", como los

(77) La Revista Católica, No 1106, "Un periódico para el pueblo", 18 de junio de 1870, p. 563.

(78) La Revista Católica, No 1112, "El Mensajero del Pueblo", 30 de julio de 1870, p. 613.

(79) La Estrella de Chile, reseña de El Mensajero del Pueblo en "Revista Bibliográfica", 3 de julio de 1870 .

(80) El Mensajero del Pueblo, N 1, "Nuestros propósitos", 10 de junio de 1870.

(81) Góngora, "Aspectos de la Ilustración Católica en el pensamiento y la vida eclesiástica chilena (1770-1814)", pp.

(82) Alejandro Larraín formó parte de la dirección de La Hermandad de los Dolores o Instituto de Caridad Evangélica, con inspiración ilustrada-católica. Ver María Antonieta Huerta, Catolicismo Social en Chile, Santiago, Ediciones Paulinas, 1991. Para la influencia de esta corriente en José I. V. Eyzaguirre ver Maximiliano Salinas, “José Ignacio Víctor Eyzaguirre (1817-1875)" en José Arteaga, José Manuel de Ferrari, Julio Jiménez, Doris Piccinini y Maximiliano Salinas, Pensamiento Teológico en Chile. Contribución a su estudio. Tomo II. Época de la Reorganización y consolidación eclesiásticas, 1840-1880, Anales de la Facultad de Teología, Vol. XXXI (1980), Cuaderno 1, Santiago, Universidad Católica de Chile, 1982, pp. 65-101. En el caso de Luis Campino no se han ensayado investigaciones que den cuenta de las influencias ideológicas, pero algo dice su acción en materias de orden educativo y su opción por la práctica de un método disciplinario persuasivo y estimulante y no centrado en el castigo corporal. Ver Virgilio Figueroa, Diccionario Histórico, Biográfico y Bibliográfico, Santiago, Balcells, 1925-1931, p. 322, vol. 2. La publicación, además, contó con un cuerpo de redactores y benefactores la mayoría pertenecientes a un círculo de familias con ascendientes influenciados por el Catolicismo Ilustrado y que ahora invertían su tiempo y dinero en la caridad y actividades educativas, incluso pensándolo al momento de establecer el destino de su patrimonio en los testamentos. En varios casos, sus descendientes participarían activamente en obras y escritos sobre problemas sociales y la democracia. Tal como ha señalado María Rosaria Stabili ciertos miembros de la elite dedicaron gran parte de sus bienes a la beneficencia y el mayor número de páginas de los testamentos precisaba detalladamente las indicaciones en torno a ella. Creemos que esto constituye un atisbo de práctica de acción social más profunda. De hecho, los testamentos que Stabili revisó arrojan que la institución más citada es la Casa Talleres de San Vicente de Paul, siguiendo los hospitales y asilos también administrados por miembros vicentinos. Ver María Rosaria Stabili, El sentimiento 
ha signado Maximiliano Salinas, aparecen en la publicación, aunque en un contexto muy distinto de la época postindependentista chilena. Siguiendo planteamientos de Sol Serrano indicamos que se puede establecer una línea de continuidad en el paso del Catolicismo Ilustrado al ultramontanismo y esa sería la referida a la relevancia otorgada a la caridad como instrumento civilizador de los pobres (83). Es probable que en 1867 no se haya pensado, porque todavía no se vivía dramáticamente y no se había conceptualizado, en el problema como una cuestión social, pero aun así, este periódico presenta muy tempranamente las preocupaciones de un catolicismo social en ciernes. Las temáticas abordadas en relación a la mejora material del pueblo, entendido en cualquier caso como carente de recursos, o bien, sin saber qué hacer con ellos, dejan entrever esta línea. El interés en la higienización de sus habitaciones, sus cuerpos y sus alimentos, junto al énfasis puesto en el trabajo, ahorro, previsión y su moralización se presentan como medios por los cuales puede mejorar su condición. El semanario no solo trató asuntos atingentes a la mejora de la condición religiosa, sino también moral y material. Sin embargo, la trayectoria del semanario cambió y pasó a seguir el programa ultramontano adaptado a un lenguaje más sencillo. En 1874 el cambio es notorio y en 1878 la publicación pasó a depender directamente de la Autoridad Ordinaria Eclesiástica" (84).

Desde Roma y desde la jerarquía eclesiástica chilena la respuesta al mundo liberal, al "espíritu del siglo", fue de batalla y de contraste. Si lo que importaba era ganar, la incógnita era evidente: ¿estaban preparados? La respuesta explica en gran parte las motivaciones de las actividades católicas emprendidas en el siglo diecinueve. Eran el resultado de una realidad: los católicos requerían instrucción en los dogmas y la fe. Ahora se imponía la militancia como requisito para ser un "sincero católico". No se trataba de captar nuevos adherentes. Los protestantes, masones o liberales - los tres enemigos de la fe- no tenían cabida en las páginas ni en los discursos de los católicos a excepción de los que proclamaban su rechazo. La prensa católica chilena del siglo era un reflejo de este punto porque su destino se había sentenciado categóricamente: combatir el error. Si bien proponemos que la prensa católica no se agota en el estudio de su ideología, creemos que el caso chileno no permite hacer las separaciones que realiza Miranda Lida para el caso

aristocrático, Santiago, Andrés Bello-Dibam, 2003, pp. 397-400. Entre los redactores y benefactores encontramos, entre otros, a Juan Ignacio González, Francisco de B. Gandarillas, Santiago Vial, Rafael Eyzaguirre, Eduardo Fabres, Camilo Ortúzar, Crescente Errázuriz, Luis Vergara Donoso, Rómulo Garrido, Manuel Sánchez Fresno, Francisco González Errázuriz, Javier Eyzaguirre, Domingo Fernández Concha, Agustín Llona, Evaristo Gandarillas, Gabriel Ocampo, María de la Cruz Arriarán, María Ossa, Blas Vial Guzmán, Rosario Fernández Concha, Rosa Concha de Fernández, Mercedes Rodríguez de Díaz, Paula Sotomayor de Rosas, Mercedes Valdivieso Cruzatt, Mercedes Agüero, Ana Brown, Maximiano Errázuriz Valdivieso, Francisco Javier Ruiz Tagle, José Clemente Fabres, Manuel José Yrarrázaval, Enrique Tocornal, Francisco de Paula Echaurren, Benjamín Vicuña Mackenna -en los primeros tiempos-, Manuel Parreño, Pedro Nolasco Vial, Silvestre Ochagavía, Ciriaco Valenzuela, Manuel Fernández Cereceda, Joaquín Echeverría, Manuel María Figueroa, Pedro Pablo García Moreno, Antonio Gandarillas, Francisco Rojas Sánchez, Mariano Sánchez, Juan B. Ugarte, Manuel Poblete, Vicente García-Huidobro, Higinio Hurtado y Benjamín Ortúzar.

(83) Serrano, Virgenes Viajeras.

(84) Artículo segundo, en Boletín Eclesiástico, "Estatutos para la publicación de El Mensajero del Pueblo", Santiago, Imprenta de 'El Correo', de R. Varela, 1884. Tomo VII, pp. 298-301. 
argentino. Postular que la prensa católica no tiene solo una dimensión política e ideológica no implica desconocer que efectivamente la tenía. Teniendo presente el caso chileno no podemos decir que se trataba de un arma de contraste a la tesis de romanización (85).

Si hablamos de mayoría, los periódicos destinados al pueblo tenían mucho que hacer. Era el campesino el que debía mantenerse firme ante un patrón que fuese masón. Era el artesano el que debía difundir entre sus pares la religión. Los habilitados para votar debían hacerlo por el buen candidato. Las mujeres, por su parte, eran las responsables de la religiosidad del marido. Los padres, del futuro religioso y moral de sus hijos. El semanario enseñaba qué responder "a los enemigos", especificar cómo debía hablar y mostrar públicamente su religión junto con aleccionar a las mujeres en el orden de su casa y en la habilidad para desempeñar su trabajo. La realidad les presentaba más obstáculos que los deseados. El desenfreno en las comidas y en las bebidas alcohólicas, el desorden y la suciedad, la prostitución y el desinterés por los trabajos serviles y la estima del lujo en las niñas pobres fueron combatidos página a página. En los años ochenta la situación cambió respecto de la instrucción religiosa y moral. El problema no eran tanto los vicios de los pobres como el voto que podían dar. En estos años, más que la regeneración y formación religiosa, importaba la "propaganda" y la opinión sobre lo contingente. Ricos y pobres, el clero y los pobres, la propaganda católica, "las votaciones", Chile en 1810 y 1883, fueron temas que ocuparon las páginas. La crónica fue fundamentalmente política. El público al que se dirigió fue mayoritariamente el masculino: el artesano y el agricultor.

La actividad de El Mensajero fue pedagógica y reformadora. El material para niños se incrementó. El público masculino se centró en los jóvenes y adultos, enfocándolos a partir de su ocupación laboral. Las mujeres adultas tuvieron también su acogida como trabajadoras, madres, esposas y como "arrepentidas", modo de referirse a las prostitutas que tenían alguna intención de reformarse. La distribución gratuita en las Conferencias de San Vicente de Paul de las parroquias, en los hospitales, cárceles y en las casas de beneficencia -de Chile y todas las de Argentina tambiénindica el público objetivo central y que se podía controlar. Ese fue el lector que se quiso formar y regenerar. La realidad que los redactores veían ante sus ojos se pensó en derrotar imponiendo modelos de virtud, modelos de artesanos, modelos de hijos, de padres, hijas y trabajadoras. Fue una herramienta pedagógica catequística, pero también de higiene, virtudes y ciudadanía.

(85) Creemos que no se puede poner en oposición a la acción de la Santa Sede porque aún los laicos tenían presente y se sentían unidos a Roma. La defensa de la Iglesia y sus derechos fue motivo de su aparición. Nosotros tampoco nos enfocamos solo en "el mundo de las ideas" ni en ver a la prensa católica solo como "arma de combate" porque las conclusiones son lógicas y carecen de sorpresa. Si bien es una tesis sugerente y novedosa, no sabemos si Miranda Lida no toma atención a casos en que la prensa depende de la jerarquía eclesiástica o bien si en Argentina la prensa católica fue iniciativa laica en su $100 \%$. En el Chile decimonónico la situación es distinta y no se puede decir que la prensa católica actuaba de "bisagra" entre la sociedad y la institución eclesiástica. Aún si las empresas estaban administradas por laicos, estaban dirigidas por sacerdotes y los periódicos más importantes dependían del Arzobispado. Ver los estudios de Miranda Lida, "La prensa católica y sus lectores en Buenos Aires, 1880-1920" y "Prensa católica y sociedad". 


\section{Católicos, virtuosos y dignos}

En los 16 años de existencia, el semanario mantuvo a la instrucción moral y religiosa como el pilar organizador de cada una de las secciones. No tuvieron un orden preciso en cada número, pero todos le daban un gran espacio junto a los artículos de higiene, medicina y agricultura. Gran parte de los primeros fue organizado en forma de cuentos cortos, poesías o experiencias cotidianas, desde las cuales se podía extraer alguna enseñanza. Esta estrategia fue totalmente planificada por los redactores, los que señalan que para inculcar al pueblo la enseñanza moral y religiosa han utilizado "la forma animada de una amena y fácil conversación", "el insinuante atractivo de una narración tierna y sencilla", o bien "la palabra más severa de una instrucción seria".

Era una "catequesis", la misma que se podía dar en el púlpito, puesta ahora en hojas y tinta. Manifiesta un programa posreforma que solo la investigación de los orígenes de las historias y el material introducido podrá confirmar (86). Con el avance de los años el semanario critica menos a Lutero que al liberalismo. Hasta 1874 la instrucción se centró en María y los santos. El Mensajero nació ante el resquemor contra el protestantismo, que osaba repartir papeluchos, que no reconocía en María a la madre virginal de Dios, que "hacía como que comía", pero no "comía" el Cuerpo de Cristo, y que interpretaba como culto de adoración lo que era la memoria de los santos. Los artículos en 1870 arrojan un 22,4\% de material que apuntaba exclusivamente al combate del "error protestante". Las historias de santos y la vida de María, junto con intentar reformar las costumbres, se convertían también en una lucha contra el protestantismo -lo indicaron en la introducción a la vida de María-. Si sumamos todo el primer año se convertía en un 32,9 el porcentaje de contenidos que luchaba por resistir las ideas del protestantismo. En 1871 y 1872 el porcentaje bajó a un $10 \%$ y un $11 \%$ publicándose además la historia de Martín Lutero desde la perspectiva del catolicismo.

Avanzando en los años de 1870, el problema del día era otro. Los protestantes atacaban la exclusividad, pero la atacaban menos que los reformadores desde las leyes. Los masones aparecieron primero. En 1875 ya habría cerca de un 4\% dedicado contra ellos. Se mantendría en estos porcentajes, combatiéndose además el liberalismo. La fecha no es casual. En 1874 se presentaron reformas político-eclesiásticas que proponían incluso la separación de Iglesia y Estado. Después de 1880, los artículos eran decididamente ultramontanos y con un alto contenido político. Se trató directamente la situación y defensa de la Iglesia, la unión y obediencia al Papa. No elucubraría sobre los fundamentos teológicos que sustentaban las posturas, pero si trataba de incorporar la idea principal: Dios y Patria. Chileno debía ser sinónimo de católico.

"Órgano de los intereses del pueblo", El Mensajero combatió el "desenfreno" en las bebidas alcohólicas. Desde su perspectiva, el pueblo no tenía "habitudes del trabajo". Se contentaba solo con "vivir" y si su existencia ya estaba asegurada no se

(86) Ver René Millar, "Aspectos de la Religiosidad". El Mensajero tomó, en los primeros años, un problema más antiguo que nuevo. 
esforzaba por más. Si trabajaba, no lo hacía con orden. Y si ganaba algunos pesos, los gastaba en "la taberna", las "chinganas" o las casas de juego, sin tener la más débil idea del "ahorro". Las mujeres eran descuidadas. Ellas, con su mal vestir y su suciedad, lograban que el marido prefiriese estar con los "compañeros" bebiendo y jugando. Ellas, al no hacer amable la vida del hogar y sí muy trabajosa, se convertían en causa de espanto del marido. Ellas, al no educar a los hijos, lograban que estos fueran unos vagos y con el tiempo, criminales. Los hijos, perdían el tiempo fuera de su casa, eran causa de desórdenes divirtiéndose matando pajaritos, dañando los árboles o en el peor de los casos, convirtiéndose en criminales. Las hijas eran reacias al trabajo de mano, gustaban de las ropas con lujo y tenían su vanidad muy desarrollada. En los tres primeros años se les quiso enseñar qué y cómo comer; a lavarse, para lo que se les indicó cómo elaborar un "jabón del pobre”; a no usar sus vestidos rasgados, sino remendados y sin manchas (87). En otro ámbito, si los niños iban a la escuela, se les incentivó a que estudiaran. Se enseñó incluso el modo de preparar tinta negra de forma económica.

La "moral en acción" apuntó al trabajo y el orden para corregir la pereza y la embriaguez. Se decía que si se juzgara el mérito de un santo por sus devotos, San Lunes sería el mayor. Tan desastroso y arraigado estaba el hábito que "las mujeres de los artesanos, cuando son honradas, ven llegar el lunes con horror, y querrían

(87) Desde 1870 a 1874 hubo más que solo moralización e instrucción religiosa. El semanario incluyó diversos artículos de higiene, agricultura, recetas de cocina y consejos diversos que denominaron "conocimientos útiles". La higiene consistió en paliar la expansión de la viruela. Ante ello se indicaba el modo de realizar el aseo de las habitaciones y de los cuerpos. Se introdujeron "recetas útiles para los enfermos" y "remedios para la peste". Se incentivó la vacunación, donde querían ser aliados de las autoridades civiles, (EMP, 10 de febrero de 1872). En 1873 se daba una "receta eficaz contra muchas enfermedades y conservar la salud", "manera de estancar la sangre de narices", "remedio para el dolor de muelas", "para curar pronto las heridas hechas con instrumentos cortantes", "manera de quitar la dentera o destemplamiento de los dientes", "medio de extraer lo que haya podido entrar en los ojos", "remedio para los oídos", "dos medios eficaces para curar las quemaduras con agua caliente", "receta para detener la picadura de los dientes" y "remedio para la picadura de abejas". Se publicaron también los medios para salvar a los ahogados por inmersión y por objetos en la garganta. Se enseñó a preparar y conservar alimentos, en vista, probablemente, de que la viruela y la disentería eran dos de las causas principales de muerte. En 1870 se insertó la forma de preparar los diversos tipos de carnes, caldos, bebidas, y otros alimentos. Se decía para qué tipo de personas eran aptos junto con la cantidad recomendada de ingesta, según la debilidad o fortaleza de las personas. Se pudo encontrar recetas para la engorda de patos y otros animales, la pericia en la distinción del vino falso, la conservación de las uvas, de huevos y pescado, además de la preparación del jamón y tortilla de maíz, (EMP, 1872. En 1873 la variedad era amplia. Se incorporaron artículos para preparar limonada gaseosa, manera de impedir que el aceite se pusiera rancio, métodos para salar y sacar el rancio de la mantequilla, junto a asuntos prácticos como el modo de sacar las manchas del vino y frutas en las manos, modo de dar consistencia a los utensilios de madera o vidrio, modo de preservar la suciedad de las moscas, modo de evitar el moho de metales, método para sacar las manchas de grasa del papel, tinta buena y barata, entre otros). Se publicó el modo de cultivar plantas, en qué época, la manera de sacar insectos y otros materiales agrícolas. No debemos olvidar que en 1875 de entre los capacitados para votar, en todas las provincias, los agricultores eran más del doble de los artesanos. El total general era, por tanto, reflejo de lo mismo: 43.724 agricultores y 24.348 artesanos (Anuario Estadístico, 1875-1876). En 1880 los artículos de agricultura tuvieron carácter renovado. Pensamos que su ampliación se utilizó como estrategia, introduciéndose incluso un sistema de preguntas y respuestas de los lectores (EMP, 15 de mayo de 1880) y se introdujo material religioso en las introducciones $(E M P, 5$ de junio de 1880). 
verlo borrado del Almanaque" (88). La crítica a la pereza se vinculó con la esencia misma del "ser ciudadano" como un miembro útil a la sociedad. ¿Qué se podía esperar de un perezoso?: "bajo cualquier aspecto no puede considerarse en él más que un hombre nulo o a lo más mediano... En cuanto a la sociedad, nada bueno puede esperar... porque no hace más ni menos que una avispa en una colmena. Ciudadano inútil y que solo sirve de carga al Estado, moriría como ha vivido, sin dejar señales de haber pasado por la tierra, si sus vicios o la suma necesidad no le proporcionasen muchas veces la energía y la triste celebridad del crimen. En efecto, el juego, el robo, el asesinato, que prefiere al trabajo, le conducen con harta frecuencia de la cárcel al presidio y del presidio al cadalso" (89).

El progreso y bienestar social se lograban mediante el trabajo, punto en el que el catolicismo se readecuaba a un interés moderno y universal: "El medio más poderoso y natural que Dios ha puesto en manos del hombre para propender a la ventura de la sociedad es el trabajo. Sin el trabajo, no se concibe progreso social de ningún género". Según el artículo, el catolicismo veía en la inacción y el ocio la debilidad, el decaimiento y la enervación. El trabajo, junto con arrojar bienes personales tenía una vinculación directa con la sociedad. Por ello, la ociosidad es declarada como un mal social y el trabajo como fuente de prosperidad pública y privada (90).

Los chilenos debían amar con mayor razón el trabajo en vez de verlo como una carga pesada. Criticaban que el pueblo tuviese una mínima necesidad de conservación porque sería el motivo de que los pobres campesinos vivieran en miserables chozas "que no son prueba muy brillante de nuestra decantada civilización: un techo delgado de paja, sostenido por algunos horcones y rodeado de una quincha, sin cubrir con barro sus muchas aberturas". Esas eran a sus ojos las casas del pobre, e incluso podían llegar a ser peores: "Y esto se ve en un país rico y no poco ilustrado. ¿No es una anomalía, que nuestra riqueza y nuestra cultura no hayan todavía desterrado semejantes chozas, indignas de los mismos salvajes de la Araucanía? La causa es que el pueblo no tiene habitudes de trabajo".

La pereza como causa de la miseria tenía clara solución para el pobre: "que no podía perder ni un día sin trabajar. Debía ahorrar, mejorar su habitación, muebles y utensilios de la casa. Atender a que la mujer y los niños tengan los vestidos necesarios, a fin de que se muden con la frecuencia conveniente y anden siempre limpios, siquiera los días de fiesta. Abstenerse de la taberna y la casa de juego era la otra cara de la medalla, junto con evitar a los compañeros de malas costumbres que lo invitaban a beber y a botar tontamente su dinero" (91).

“AAl trabajo! ¡Al trabajo!”, pero ¿qué trabajo le correspondía al pobre?, ¿al hijo del carpintero?, ¿a la hija de la lavandera? Lo ordinario y común era que desempeñara el mismo oficio de sus padres, que fuera artesano o lavandera también. Los "padres sin seso" que piensan en enviar a sus hijos al Instituto o al

(88) El Mensajero del Pueblo, 24 de septiembre de 1870.

(89) El Mensajero del Pueblo, 1 de octubre de 1870.

(90) El Mensajero del Pueblo, "El Trabajo", 19 de junio de 1880.

(91) El Mensajero del Pueblo, "El Trabajo", 26 de junio de 1880. 
Liceo, o a la "hijita" al colegio solo lograrán que su hijo se convierta en un vagabundo y una peor suerte para las niñas (92). La educación debía ser fundamentalmente técnica y, de hecho, eran oficios los que se enseñaban en las Escuelas Talleres de San Vicente de Paul. Vale señalar que esta era la forma de mejora social pensada: mejora de las condiciones materiales, pero ello no implicaba incorporar la idea de un cambio de oficio.

La existencia de un buen artesano y una lavandera moral se lograrían, sobre todo, si se educaba a los niños y niñas. Los peligros eran muchos: los niños al crecer se podían convertir en criminales. Las niñas: era mejor no decirlo. Ciertamente, en el período, la criminalidad y la prostitución se convirtieron en un problema que escandalizaba a la sociedad. Las prostitutas debían extirparse o esconderse de alguna forma, y la visión de las elites decimonónicas fue de rechazo (93). El semanario, ante este problema, tuvo una clara estrategia. La importancia de la "inocencia" y de la "piedad" de la niña tenía una explicación clara en su realidad social (94). Pensamos que los artículos marianos destacando la pureza y virginidad tienen relación directa con el problema de la prostitución.

La niña debía ser decente y debía mantenerse limpia. Una cosa era la pobreza, pero otra muy distinta "la desidia". Un ejemplo de instrucción al respecto es el poema titulado "La Limpieza" (95). La mujer, sin importar cuán pobre fuese, no podía añadir a ello la suciedad ni la irreligión. Se criticó, a la vez, que las "niñas pobres" pidieran ropas lujosas a las madres para asimilarse a las demás. El problema era mucho mayor en las escuelas donde se generaba una competencia de la vanidad (96). No era malo, sino incluso bueno que la mujer cultivara la inteligencia "con el aprendizaje de algunos ramos del saber, como la geografía, la historia, la gramática y otros", no obstante, "todo esto, sin la incesante represión de su vanidad, sin moderar la exaltación de su loca fantasía y de su corazón, ávido de emociones, no hará más que jóvenes presuntuosas y altaneras”. El resultado sería la desgracia de la familia y de la sociedad. Por ello, "el trabajo de manos es absolutamente necesario para la mujer, por la condición misma de su ser moral, tan inclinado a la disipación y a los placeres" (97).

En el caso de las mujeres adultas, el modelo era el de una mujer capaz de gobernar el hogar, contenedora de los vicios del marido y educadora de los hijos

(92) El Mensajero del Pueblo, "El Trabajo es Honroso", 3 de julio de 1880.

(93) Ver Álvaro Góngora, La prostitución en Santiago, 1813-1931: Visión de las élites, Santiago, DIBAM, 1994.

(94) La inocencia y la fe son los dos pilares básicos de todos los artículos relativos a la educación de la mujer.

(95) La limpieza en las niñas/bien calculada/le da gracias al cuerpo/belleza al alma/Procura, empero/ las gracias en el alma/más que en el cuerpo. Lavarte cada día/debes la cara/que es del alma un espejo/según la fama/y es, niña bella/preciso que esté siempre/limpia como ella. En lavarte las manos/sé cuidadosa/que unas manos tiznadas/son asquerosas/las uñas largas/nunca, aunque fuere moda/debes llevarlas. El pelo bien peinado/ten, hija mía/ que indica el pelo suelto/mucha desidia/ $\mathrm{Y}$ es cosa clara/que es más bella una niña/limpia y peinada Niña sucia y desgreñada/por ninguno es bien mirada/pero, si está peinada y bien vestida/de amigos y de extraños es querida. El Mensajero del Pueblo, 1 de octubre de 1870. Versos en alineación separada en el original. Cursivas en el original.

(96) El Mensajero del Pueblo, "Las niñas de las escuelas", 26 de abril de 1873.

(97) El Mensajero del Pueblo, 3 de junio de 1880. 
(98). En sus manos estaba el porvenir de las familias: podían ser la ruina, o bien fuente de bienestar si se aplicaban a la labor, al hilo y al orden de sus materiales de trabajo.

En el caso de niños y jóvenes, debían enterarse que la virtud se ejercita "ahora". La idea de que la juventud era la edad para el ocio y los vicios que rechazó, pues estos se arraigarían y la voluntad perdería vigor (99). Se impuso el modelo del joven "hijo del pueblo" como un varón trabajador y sobrio. El poema de Carlos Walker Martínez publicado en una colección, se imprimió también en las páginas de El Mensajero y en otras publicaciones católicas posteriores. Fue la imagen que el catolicismo esperó del joven obrero, primero ante Dios "cuando es virtuoso" (100).

El semanario tradujo así el interés generalizado del catolicismo de fines de siglo. No es casual que los círculos de artesanos hayan cobrado vigencia. Y no es casual que San José y Jesús hayan sido personificados como carpinteros. Las primeras sociedades de artesanos fundadas en Chile se remitirían al nombre de Sociedad de Artesanos de San José, que contó con bendiciones eclesiásticas particulares. El Mensajero se convirtió en un avisador permanente de las actividades patrocinadas por la sociedad como de sus retiros, porque el obrero, junto con aprender el orden y el trabajo, debía ser "buen cristiano" y "buen ciudadano" (101).

\section{Un ciudadano patriota}

"El más bello país del universo" (102) se constituía en el motivo ideal para formar a "los buenos cristianos y a los buenos ciudadanos" (103). El semanario consideró relevante la difusión del "amor a la patria" y la responsabilidad ante los deberes cívicos. La canción nacional y la imagen del escudo patrio fueron consigna-

(98) Un ejemplo lo tenemos con el siguiente corrido campesino: "Sábado cuando coge/ mi maridito el jornal/ Deja allá a sus compañeros/ que a la taberna se van/Y trago va, trago viene/ su jornalito a gastar;/ y él me lo entrega todito/ Medio a medio y real a real/-toma, hija mía, me dice/compra carne, compra pan/compra lo que te haga falta/que tú muy bien lo sabrás/ Y yo le respondo haciendo montoncitos el jornal:/-con esto pagas las deudas/que tenemos que saldar/ esto es para el casero/ esto es para carne y pan/Estotro para guardarlo/Por si Dios nos diese un mal/Y todas las mañanitas/por mis puertas han de entrar/como el orito la carne/y como la nieve el pan/y al ver esto mis hijitos/iqué saltar y qué brincar!/Y me dirán las vecinas/llenas de curiosidad/-Tu marido y tus hijitos/como el sol de Dios están/¿Qué les das tú, vecinita?/¿Vecinita, qué les das?/Pues ya los nuestros se mueren/De frío y necesidad/-Pues yo les doy, les respondo/ Buen gobierno, y nada más". El Mensajero del Pueblo, "el buen marido y la mujer feliz", 26 de noviembre de 1870.

(99) El Mensajero del Pueblo, "A cada edad, lo que le es propio", 10 de julio de 1880.

(100) "Nació pobre, pero honrado/No meció su humilde cuna/la diosa de la fortuna/cegada por la ambición/pero aunque pobre en riquezas/rico en nobles sentimientos/a muy altos pensamientos/ levantó su corazón /Desde niño en el trabajo/supo ganar diariamente/con el sudor de su frente/el pan que le dio el taller/del taller salió formado/el ciudadano y hombre/sin una mancha en su nombre/ni una sombra en su honradez /En el altar de la patria/se formó buen ciudadano/virtuoso, digno, cristiano/generoso y varonil/supo cumplir sus deberes/y abrió a su paso el sendero/de un hermoso y lisonjero/lisonjero porvenir/¡Honor al hijo del pueblo/que en el trabajo se eleva/y en él engrandece y prueba/su abnegado corazón! /¡Honor al obrero honrado/que su conciencia levanta/bajo la bandera santa/de su Patria y de su Dios!". El Mensajero del Pueblo, 18 de septiembre de 1873 .

(101) Los artículos de la sociedad de obreros lo declaran como los deberes para poder ser miembro.

(102) El Mensajero del Pueblo, 18 de septiembre de 1873.

(103) El Mensajero del Pueblo, 5 de julio de 1870. 
das en cada uno de los números correspondientes a las fiestas patrias. Se incluyeron artículos especiales en los que se exaltaban las bellezas del país comparándolas con las catástrofes de los vecinos. Chile no era como ellos. Chile contaba con la mano divina que lo había convertido en un país bello. La celebración de la independencia llamaba a expresar el justo amor que se le debe rendir al suelo patrio: "Cada vez que, sobre nuestras nevadas cumbres, se alza este bello sol de septiembre, nuevos sentimientos renacen en el alma, nuevas emociones nos agitan; y aunque miles de años transcurran para Chile después de 1810, la distancia del grandioso acontecimiento de nuestra emancipación política nada hará perder de sus encantos a la fiesta de todo un pueblo ni a los dulces recuerdos que ella evoca... no hay un amor grande, inmenso en los hijos de Chile, ese es el amor a la patria. Amor justo, amor santo, amor que Dios bendice y recompensa. El que no ama... diríamos de él que no tiene corazón ni es digno de habitar bajo el cielo de Chile. Si eres cristiano y te glorías de serlo, debes también gloriarte de ser un buen patriota" (104). Se publicó la historia de "los presidentes de Chile bajo la dominación española" y de "los presidentes de Chile" con una clara intención de pedagogía cívica y exacerbación del amor patrio. Se indicaba el bien que el personaje prodigó a la patria y las obras de hermoseamiento material o sucesos bélicos importantes en los que se habían conquistado glorias para Chile. Ese patriotismo era el que se debía imitar.

Educación o pedagogía cívica que se entiende en función de la construcción de un nacionalismo católico. Carmen Mc Evoy ha destacado la importancia del discurso católico frente a la generación del nacionalismo. Según la autora, Benedict Anderson no habría tomado razón de que la religión jugó un papel de primera importancia en la formación de un ideario nacionalista, lo que se reflejó sintomáticamente durante la Guerra del Pacífico (105). La "comunidad imaginada" se desplegaba sobre todo en momento de una guerra. Sin embargo, la dualidad de Dios y Patria, se estaba gestando desde antes de pensar en la posibilidad de un conflicto bélico o de una expansión territorial. La guerra que unió Dios y Patria fue la entablada entre un catolicismo que buscaba la permanencia de un Estado Católico y un Estado que buscaba la laicidad. Es en 1870, a la llegada de los enviados chilenos al Concilio Vaticano Primero, cuando Carlos Walker Martínez indica que la tradicional consigna del joven "por Dios y su Dama" debe ser cambiada por "Dios y su Patria" (106).

La guerra del Pacífico exacerbó y fue "circunstancia favorable" para un discurso que ya se había gestado. De ahí que el semanario se una al deber de ver en el triunfo la obra de Dios y llevar una conducta adecuada a los prodigios divinos: "El chileno que, en estos momentos solemnes, no ve algo más que obra del hombre, en la desigual lucha en que la Patria está empeñada, carece de fe y es un ingrato. Y, a la

(104) El Mensajero del Pueblo, 18 de septiembre de 1873.

(105) Carmen Mc Evoy, "De la mano de Dios. El Nacionalismo católico chileno y la Guerra del Pacífico, 1879-1881", en Bicentenario. Revista de historia de Chile y América, vol. 5, n 2 . Si bien la autora pretende refutar el modelo andersoniano, ella no toma cuenta que el catolicismo ya no era el mismo y había entrado en la esfera pública con medios modernos, especialmente la prensa. Ver Sol Serrano, "La definición de lo público en un Estado católico" y "El poder de las palabras".

(106) La Estrella de Chile, 1870. 
acción de gracias hay que añadir la súplica... Y no solo la súplica, animada del amor y de la esperanza, sino también una conducta cristiana, es nuestro deber en la hora presente. ¡Cómo! Pretender que el Dios de bondades continúe prodigándolas a Chile, merced a nuestra plegaria, mientras las obras son indignas y ultrajan el nombre del Padre de quien todo lo esperamos, sería necia locura" (107).

En 1880 se revivía lo que había sido enunciado años antes de la guerra. Dios es la causa del progreso chileno, pero ahora esta unión de Dios y Patria que podía resultar artificial anteriormente, tenía una prueba evidente: "es lo que ha podido llevar a este tan querido suelo de la patria de progreso en progreso, hasta ponerlo a la cabeza de todos los otros países hermanos y que empezaron a vivir a un tiempo con él la vida de naciones autónomas y soberanas...". La "dualidad santa" de Dios y la Patria permitía que Chile no estuviese en la "extremidad tristísima" de Perú y Bolivia "que de un momento a otro pueden ser borrados del mapa universal de las naciones por la espada vencedora de los chilenos" (108). La deuda era clara y así lo debían entender tanto el pueblo como el gobierno: Y ¿a quién somos deudores de esta gloria? Sin duda que al heroísmo de nuestros soldados... Pero, sobre el valor y fuerza de los ejércitos, está la mano divina... Y es Dios el que ha depositado este amor patrio y esta generosidad que no reconoce peligros cuando se halla por medio la honra de Chile... Bien lo ha comprendido gobierno y pueblo, sacerdotes y simples fieles, que, en las primeras horas de su regocijo, se encaminaron al templo y, postrados ante el Supremo Monarca del universo, reconocieron que a Él todo debían" (109).

Sin embargo, el gobierno que se encaminó al templo parecía no vincular todas las exigencias que el ultramontanismo atribuía a "Dios y Patria". Menos aún al ver que Domingo Santa María se perfiló como candidato presidencial. El Mensajero develó en este momento una clara intención: unió al prodigio divino del triunfo en la guerra el deber de votar por el candidato de la Religión: "De otro modo, sería muy posible que, después de haber colocado tan alto los hijos del pueblo el nombre de Chile en los campos de batalla en tierra extraña, viniesen a usufructuar esas glorias unos cuantos ambiciosos que ningún sacrificio han hecho por la Patria y que apetecen el poder nada más que para su medro personal y satisfacer sus odios de partido. Y ese sería el triste resultado de la indolencia de los ciudadanos, que no se preocupan de la elección y de dar su voto por el nombre más digno". La elección del Presidente de la República es "la obra de cada uno de los hijos de Chile, sea cual fuere su clase y condición, con tal que reúna los requisitos que la ley exige". Los "chilenos" no deben olvidar que se trata de la suerte de la "querida Patria", por lo que "únicamente -se debe tener- en mira los sagrados intereses de la Religión y del país". El voto al "buen candidato" -se eligió a Manuel Baquedano- no era solo un derecho, sino "un deber imprescindible" (110) del buen ciudadano.

(107) El Mensajero del Pueblo, 13 de septiembre de 1879.

(108) El Mensajero del Pueblo, "En el día de la Patria", 18 de septiembre de 1880.

(109) El Mensajero del Pueblo, "Chile es invencible", 5 de junio de 1880. N 458.

(110) El Mensajero del Pueblo, "Las votaciones", 14 de mayo de 1881. 
Más allá de la cordillera. La ruta del Mensaje y sus lectores

¿Quiénes eran los llamados a la virtud, a la civilización, a la buena ciudadanía? Para responder esta pregunta no basta con saber cuáles eran los contenidos que se aprobaban en la casa del presbítero y que se tiraban en alguna de las imprentas con dueños católicos. Ese era el primer recorrido del semanario pero, ¿después qué? El semanario estaba pensado para evitar los problemas del proceso de industrialización y urbanización. Se desincentivó la migración de los provincianos, y se prefirió mostrarles las bondades de su situación actual y las desventajas al ir a hacinarse a las ciudades con mayor aglomeración. En zonas urbanas se centró en hacer llegar la publicación a niñas y niños, en los artesanos y en los que habían roto las leyes humanas y divinas -criminales y prostitutas-o bien no podían insertarse en el ritmo de la utilidad y la eficiencia del trabajo, los enfermos, mendigos e inválidos. A ellos se les pretendió formar y regenerar en el trabajo, en el orden, el ahorro y la sobriedad. Ellos serían así los "buenos ciudadanos chilenos". La circulación del semanario muestra un público diverso. El análisis de los contenidos prueba lo mismo. Ello prueba que existe concordancia entre las redes de difusión y los contenidos del semanario. Esta constatación implica decir que los primeros propósitos expuestos por los redactores se quedaron cortos. El contraste de lo que realmente se publicó junto con las redes de circulación refleja que se pensó, sobre la marcha, en un pueblo mucho más amplio que el comprendido solo por el "masculino-trabajador", el único esbozado en los inicios.

Se logró una red nacional e internacional que alcanzó a todas las parroquias, a cárceles, hospitales y casas de beneficencia chilenas (más de 175 lugares) y a unas cuantas ciudades latinoamericanas. Tanto Ecuador como Perú, Argentina y Uruguay contaron con ejemplares de la publicación. En el primer país, Loja, Cuenca y Riobamba recibirían la colección de todos los números del año 77. En Perú, Huaraz, Arequipa e Iquique adquirieron el semanario. En Argentina, Buenos Aires y Córdoba lo recibieron al menos desde 1874, y en 1876 la primera contaría con 37 ejemplares a la semana para difundir entre todos los hospitales y casas de beneficencia gratuitamente. En Uruguay, Montevideo tuvo el semanario desde 1870 y en 1871 sacó una publicación homóloga a la chilena adaptada a su propia realidad (111). Si bien la difusión internacional no fue continua a través de los años, podemos ver que el interés básico era mostrar el semanario como ejemplo a los obispados para que pudiesen formar una publicación similar en sus países, tal como lo hizo Monseñor Jacinto Vera de Uruguay (112). Ello motivó también a los redactores chilenos (113).

(111) Los redactores chilenos comentaron a su "colega", indicando que es un "motivo de gran satisfacción y purísimo gozo... ver reproducida su idea en una de las repúblicas hermanas". El Mensajero del Pueblo de Montevideo difundiría y desarrollaría el ideal de la civilización cristiana "más allende los Andes y los mares" entre "el mercader y el artesano, el gañán y el labrador". El Mensajero del Pueblo, 15 de abril de 1871, Año I, N ${ }^{\circ} 41$.

(112) Monseñor Jacinto Vera parece haber seguido el modelo chileno en Uruguay. Fundó La Revista Católica en 1860, El Mensajero del Pueblo en 1871 y El Bien Público en 1878.

(113) En El Mensajero del Pueblo, 31 de diciembre de 1870, se indica que la difusión internacional les sirve de incentivo a la continuación del trabajo periodístico en Chile. 
La red nacional fue amplísima. Muy amplia en contraste con lo que se venía haciendo. Si bien la prensa es un fenómeno básicamente urbano y los promedios de difusión del semanario no prueban otra cosa, la extensión que alcanzó no deja de sorprender. Desde los primeros números se gestionó su llegada a todas las parroquias del país, convertidas en puntos de suscripción. Desde el número 14 se adhirieron 10 personas, que funcionaron como agentes, y en 1875 pasaron a ser 27. La diversidad de lugares y concentración de semanarios se sitúa entre las regiones $\mathrm{V}$ y VIII, que ostenta el $84 \%$ de todos los puntos de la república (114). En Santiago hubo 34 lugares de venta y 7 para la suscripción, entre boticas, cigarrerías, librerías y la imprenta de El Independiente hasta el número 14. A partir de ese día anunció que se encontraría en 48 puntos de toda la ciudad de Santiago. Entre ellos nos encontramos con una de las dulcerías que sería famosa por su gran concurrencia popular (115) y también con sectores que comprendían los barrios de Yungay, la Chimba y Cañadilla (116). Los redactores se impresionaron y señalaron que "El Mensajero del Pueblo ha alcanzado una difusión que no esperábamos" por lo que "se han agotado por completo algunos números" y que, debido a las peticiones, se ha comenzado la segunda edición (117). Con todo, hubo necesidad de una tercera.

Las redes construidas tienen directa relación con el objetivo de la publicación de ser funcional a los dos puntos clave de las políticas diocesanas: la formación de los sacerdotes y el fortalecimiento de la actividad parroquial. Todas las parroquias contaron con al menos un ejemplar, suministrándole al párroco el material catequístico necesario. Se incentivó su empastado por lo que hubo interés en que se convirtiese en un "libro de consulta". ¿Cuántos semanarios estuvieron disponibles por parroquia? Si bien la mayor difusión de la publicación se concentró definitivamente en Santiago, el análisis de las suscripciones y su distribución en el país muestra que se intentó cumplir el objetivo de "difusión a provincias". Por ejemplo, en 1875 del total de suscriptores, un 45,4\% (990.7 de 2.181) se destinó fuera de los límites de la capital del país. En 1875 el Obispado de La Serena contó con poco más del doble de semanarios que de parroquias, pues los ejemplares disponibles fueron 27,9 contra 12 de las parroquias. La cifra es ínfima pues la población total era de 229.475 personas. Contrastando las cifras con el índice de individuos capaces de leer, los análisis resultan más felices, pero no por ello menos exiguos. De hecho, se encuentra un semanario por cada 2.731 lectores potenciales (118). Si pensamos en que llegaba un semanario a cada habitación de los suscriptores se puede señalar también que los informados de los contenidos

(114) El total de lugares a los que llegó en provincias es de 156, pensando solo en las que tuvieron suscripciones (pues llegó a todas las parroquias). Se han excluido las casas de beneficencia de provincias y se incluyó a las zonas de la Región Metropolitana "rural".

(115) Nos referimos a la dulcería de Antonia Tapia, la que según Luis Alberto Romero fue un punto de sociabilidad popular.

(116) Ciertas comparaciones pueden resultar significativas en este sentido. Sabemos que La Estrella de Chile en 1867 solo contó con dos puntos de suscripción en Santiago y con ocho en 1869, El Obrero Católico de Talca (1867-1868) con tres como máximo, La Revista Católica con cinco.

(117) El Mensajero del Pueblo, 6 de agosto de 1870.

(118) Estamos ocupando las cifras de personas que "saben leer", un poco más alta que el índice de alfabetismo que incluye a los capaces de escribir. En Coquimbo y Atacama la cifra asciende a 76.221 habitantes. Ver Anuario Estadístico, 1875-1876, pp. 111-121. 
subían a 140 personas (119). La zona entre el Arzobispado de Santiago y el Obispado de Concepción muestra que se contó con 831,4 ejemplares para 252.751 habitantes que saben leer, lo que corresponde a un semanario por cada 304 lectores potenciales y de 5.612 posibles enterados (120). En el Obispado de Ancud había 131,4 ejemplares para un total de 52.227 personas que sabían leer. Vale decir un semanario por cada 398 personas lectoras y un universo potencial de 756 personas enteradas (121). Un análisis más parcelado por ciudades nos indica que Valparaíso y Concepción contaron con el más alto número de semanarios. A la primera ciudad llegaron un poco menos de 90 ejemplares, mientras que a Concepción las suscripciones ascendieron a más de 140 en promedio (122). Con todo, no hubo un exceso de semanarios ni en Valparaíso ni en Concepción, ni en ninguno de los demás pueblos, villas o lugarejos. Las cifras ayudan a hacer tangibles las palabras de los redactores respecto de la difusión (123). Se concede que al tratarse de suscripciones, esta propagación se convirtió en una entrega "personalizada" de los semanarios, eliminándose con mucho la posibilidad de la existencia de ejemplares estancados en su punto de venta.

\section{Promedio semanarios, 1875-1881}

Zona Norte: Chañaral, 0,3; Choapa, 0,9; Coquimbo, 2,4; Illapel, 1,7; La Serena, 21; Los Vilos, 0,3; Quilimarí, 3,1

Quinta Región: Algarrobo, 4,7; Calera, 0,1; Cartagena, 0,6; Casablanca, 7,4; Catemu, 0,4; Chagres, 0,3; Curacaví, 14,2; La Ligua, 8,4; Limache, 13,3; LlaiLlai, 1,1; Los Andes, 21; Malloco, 3; Peñablanca, 0,3; Petorca, 10,9; Puchuncaví, 0,1; Putaendo, 3,7; Quillota, 9,3; Quilpué, 0,1; Quintay, 0,3; San Antonio, 5; San Esteban, 2,9; San Felipe, 17,3; San Roque, 0,1; Valparaíso, 85; Purutún, 0,4 ; Curimón, 0,4

(119) Esto lo decimos pensando en la real posibilidad de que se cumpliesen las recomendaciones del semanario que impulsaba a que el miembro lector de la familia lo leyese al resto. Por ello consideramos el promedio de personas por habitación en Coquimbo y Atacama que es de 5 personas. (4 en Atacama; 6 en Coquimbo). Además de ello, recordemos las palabras de los directores "nuestro periódico... es recibido con profundo cariño en la modesta morada del pobre, en los queridos asilos de los enfermos o afligidos, en los tristes recintos en que la justicia humana encierra a los desgraciados que han infringido sus leyes". Ver El Mensajero del Pueblo, $\mathrm{N}^{\circ}$ 142, 14 de junio de 1873 .

(120) No se incluye a Santiago en el análisis. El promedio de personas por habitación es de 6,75. Cf. Anuario Estadístico, 1875-1876.

(121) El promedio de personas por habitación es de 5,75. Cf. Anuario Estadístico, 1875-1876, pp. 111-121.

(122) En el caso de Valparaíso, la ciudad contó con índices de alfabetismo similares -incluso mejores en ciertos casos- a los de Santiago. De hecho, en 1875 el índice de mujeres lectoras en Valparaíso era mejor que el de hombres en Santiago. En Santiago leían uno de cada 2,7 hombres y en Valparaíso una de cada 2,6 mujeres. El número de hombres que leían en esta última correspondía a uno de cada 2,9; apenas 0,2 puntos de diferencia con Santiago. En la capital, eran capaces de leer una de cada 2,9 mujeres. Cf. Anuario Estadístico, 1875-1876, p. 120.

(123) Especialmente cuando señalan que la publicación hace un bien en las provincias y cuando indican que de "los lugares y parroquias más apartadas" reciben noticias de "este pequeño periódico". El Mensajero del Pueblo, 7 de julio de 1876. La frase se adjuntaba a la petición por los pagos de los compromisos asumidos por lo que también pudo consistir en una sutil persuasión o llamado a la conciencia, tratando de mostrar que se perdería todo ese bien que se estaba logrando. 
Sexta Región: Auquinco, 0,1; Cáhuil, 0,1; Chépica, 0,7; Chimbarongo, 4,7; Cocalán, 0,3; Codegua, 1,6; Coínco, 1,1; Coltauco, 3,9; Cunaco, 0,1; Doñihue, 2,3; Guacarhue, 5,7; Gultro, 0,3; Lolol, 4,1; Malloa, 2,9; Miranda, 0,1; Nancagua, 2,6; Navidad, 3,7; Palmilla, 3,1; Paredones, 0,3; Pelequén, 2,6; Peumo, 0,7; Pichidegua, 0,6; Placilla, 0,1; Pumanque, 3,7; Rancagua, 8,4; Rengo, 4,5; Requínoa, 7; Rosario, 1,3; San Fernando, 39,1; Santa Cruz, 1,1; Tagua Tagua, 3,3

Séptima Región: Cauquenes, 14,1; Chanco, 2,3; Constitución, 13,6; Curepto, 6,4; Curicó, 13; Empedrado, 0,7; Licantén, 1,1; Linares, 6,9; Loncomilla, 3; Lontué, 1,1; Molina, 2,4; Parral, 0,1; Pocillas, 3,9; San Clemente, 5,7; San Javier, 0,1; Sauzal, 0,9; Talca, 14,9; Talpén, 1,3; Teno, 4,6; Tutuquén, 15,4; Vichuquén, 10,9; Villa Alegre, 3,7; Yerbas Buenas, 21,4

Octava Región: Arauco, 9,7; Bellavista, 0,1; Bulnes, 6,6; Cañete, 2,4; Carampangue, 0,6; Chillán, 35,7; Chillán Viejo, 2,7; Cobquecura, 1,4; Coelemu, 2,3; Concepción, 142, 7; Copiulemu, 1; Coronel, 5,7; Florida, 4,9; Hualqui, 1,9; Lebu, 15,9; Los Ángeles, 28, 3; Lota, 3,3; Mulchén, 1,6; Nacimiento, 9,3; Ninhue, 0,3; Paico, 0,3; Pemuco, 3,1; Penco, 2,6; Quillón, 8,9; Quirihue, 1,6; Ranquil, 0,6; Rere, 13,9; San Carlos, 20; San Pedro, 0,3; Santa Bárbara, 5,1; Santa Juana, 3,3; Talcahuano, 9,4; Talcamávida, 5,4; Tomé, 12,9; Tucapel, 0,9; Vegas de Itata, 2,9

Regiones IX, X y XII: Angol, 0,9; Collipulli, 0,4; Toltén, 1,6; Achao, 0,4; Ancud, 20,7; Calbuco, 0,1; Castro, 6,4; Chelín, 1,4; Chonchi, 1,6; Corral, 0,4; Dalcahue, 0,1; Maullín, 0,3; Osorno, 49,6; Puerto Montt, 15,1; Valdivia, 23,7; Magallanes, 8,6; Punta Arenas, 0,1

Región Metropolitana Rural: Aculeo, 0,3; Alhué, 0,9; Buin, 4; Colina, 3,3; Curacaví, 12,3; Linderos, 16,4; Melipilla, 13,4; Paine, 0,1; Peñaflor, 0,4; Renca, 1,6; San Bernardo, 4,9; Mostazal, 0,7; Maipo, 19; Talagante, 0,3

Fue Santiago la ciudad que concentró el mayor número de ejemplares. En el triángulo de la "ciudad propia", área comprendida entre la Cañada (Alameda), Mapocho y Negrete, se perfiló la distribución de 7 puntos de suscripción y venta de números sueltos. Fuera de ella, el semanario se extendió a zonas de crecimiento popular. El barrio de Yungay, aposento de los "pobres decentes" en 1841, pero convertido en los 70 en un arrabal en la parte baja y en un fangal en su límite oeste, junto a la Chimba y la Cañadilla contaron con seis puntos de venta de números sueltos, sin posibilidad de suscribirse. El número de suscriptores, de los cuales descontamos a los accionistas, fue un número alto, incluso cuando el semanario comenzó su crisis. En general, los periódicos en la primera mitad del siglo no alcanzaron los 300 suscriptores. En el caso de El Ferrocarril sabemos que comenzó con 300 en el período previo a su fundación y llegó a los 400 para la fecha en que se difundió su prospecto (1855). Las esperanzas se centraban en lograr entre 500 y 1.000 suscriptores (124). El Mensajero del Pueblo 
comenzó con 2.400 suscriptores aproximadamente. Los bajó, entre junio de 1871 y junio de 1872 , a 1.900 , y a 1.280 en el año siguiente, pero luego repuntó a 1.838 , entre junio de 1874 y junio de 1875 , y a 2.181 entre 1875 y 1876 . A partir de ese año la tendencia sería a bajar a 1.600 aproximadamente entre 1877 y 1878 y a los 628 en 1879-1880. De estas cifras, en 1875 Santiago contó con 54,6\% de las suscripciones totales. Para ese mismo año, si de los 3.500 ejemplares impresos descontamos los 990.7 correspondientes a provincias, resulta que la oficina de El Mensajero proporcionó a Santiago un semanario por cada 52 personas, aptas para leer, vale decir un universo de 15.056 personas podían enterarse de los contenidos del semanario (125).

Esos son una muestra de los análisis que parecen pertinentes respecto a las suscripciones y la venta de números sueltos. Ahora bien, el semanario también tuvo una red de circulación gratuita. Esta comprendía las casas de amparo de las "niñas inocentes" y de las mujeres "arrepentidas". En general se ha sentenciado que estas obras de beneficencia se ocuparon de encerrar lo que no era grato en una ciudad moderna. Gabriel Salazar y Julio Pinto lo han destacado con bombos y platillos: "la caridad decimonónica y sus "señoras" manifestaron esa actitud: el horror ante su brutalidad, y la necesidad de construir casas de huérfanos, de poner a las "chinas" a trabajar en casas respetables, de sacar a los vagos de las calles" (126). Paternalismo puro tras la idea de un pueblo borracho, ignorante e inmoral. Ciertamente, los sacaron de las calles, pero también pensaban en dejarlos aptos para salir. Desde 1871 (en todo caso, es altamente factible que haya sido desde los primeros números) la publicación informa que entrega 20 ejemplares a la Casa del Buen Pastor de Santiago que se ocupaba precisamente de asilar a "niñas inocentes" y "mujeres arrepentidas". Junto a ella, en 1875 se comenzaría a repartir a la Casa de María, ocupada en la atención de niñas desamparadas. La primera institución mantuvo entre 100 y 150 asiladas entre 1869 y 1877 y aunque no se tienen datos de instrucción para este sector es probable que todo el grupo se enterase de los contenidos. Enriquece este punto la constatación de que el semanario dedicó alrededor de un $20 \%$ y un $10 \%$ de material dedicado directamente a niñas en la mayoría de sus números y en total, alrededor de un $30 \%$ exclusivamente a un público femenino en su calidad de trabajadoras. Las niñas tuvieron secciones especiales con carácter permanente, punto que también se convierte en indicador de que se lograban resultados satisfactorios en ellas. En el caso de las arrepentidas, estas no contaron con secciones particulares en forma permanente, pero sí podían ser receptoras de los artículos dedicados a las trabajadoras. Los niños, por su parte, también se convirtieron en un foco de atención. El Patrocinio de San José, dedicado a la instrucción primaria y técnica, comenzó a recibir semanarios gratuitamente desde 1874. Es interesante indicar que El Mensajero fue ocupado como una herramienta funcional a la realidad. Existían niñas bajo la tutela de instituciones religiosas y en atención a ello la publicación se permitió incorporar material que fuese en directa colaboración con el trabajo que aquellas realizaban. Los niños desamparados

(124) Ver el análisis del prospecto en Cherniavsky, "El Ferrocarril", p. 97.

(125) La cifra de personas que saben leer en Santiago asciende a 130.739. El promedio de personas por habitación es de 6.

(126) Gabriel Salazar y Julio Pinto, Historia Contemporánea de Chile II. Actores, identidad y movimiento, Santiago, LOM, 1999, p. 55. 
no contaron con una institución religiosa particular, aparte del asilo de San José, siendo acogidos básicamente en las casas de expósitos. Se debe destacar que cuando se incorpora el Patrocinio a las redes de difusión, las lecturas directamente para niños aumentan y aparecen las secciones "consejos de un padre a su hijo" y "lectura para niños", sin que desaparecieran las dedicada a las niñas.

Otras instituciones atendidas fueron los hospitales. Al menos desde 1871 se repartieron 40 ejemplares al de hombres (San Juan de Dios); 20 al de mujeres (San Borja) en Santiago y la misma cantidad al hospital de Valparaíso. Se incorporarían el de Valdivia en 1876 y el de Rancagua en 1877. Los hospitales tenían una entrada variable, alrededor de 20.000 personas dentro de los hospitales que nos atañen (127). Sin embargo, aquí tampoco contamos con los datos de instrucción, pero sí con el número de oficios de los internos. Ello nos indica reveladoramente lo mismo que ocurría con las casas de beneficencia anteriores. Los redactores escribían para la realidad que ellos o sus cercanos atendían. En 1870, entre los hombres hospitalizados la escala de los tres oficios con mayor cantidad corresponde al de gañanes, agricultores y comerciantes; entre las mujeres la escala otorga a las sirvientas y costureras el mayor número (128). El escenario del hospital es una muestra representativa del teatro más amplio que constituía la sociedad chilena, pues gañanes, agricultores, artesanos y comerciantes componían los oficios mayoritarios en los hombres (129), mientras que el de costureras, sirvientas y lavanderas arrojaban los más importantes para las mujeres (130). Además es pertinente anotar que en el período, los carpinteros, artesanos, zapateros y agricultores daban forma a las más altas cifras de criminalidad (131). El semanario repartió 45 y 48 ejemplares entre la Casa de Corrección, la Penitenciaría, el cuartel de policía y la Cárcel Central. Evidentemente quería desplegar una labor preventiva, pero además regenerativa de los miembros de la cárcel. A la Penitenciaría de Santiago se entregaban 30 ejemplares. En 1870 mantuvo un total de 513 personas, de las cuales 122 sabían leer (132). Esto significa que se contó con un ejemplar para 4

(127) Calculando en 1875 tenemos que al de hombres entraron $5.711 \mathrm{y}$ al de mujeres 8.057. Al de Valparaíso ingresaron 3.285 hombres y 1.462 mujeres y al de Rancagua 784 hombres y 497 mujeres.

(128) Anuario Estadístico, 1870-1871, "Beneficencia".

(129) Como indicaban los redactores en los primeros tiempos, se buscaría "al mercader y al artesano; al labrador y al gañán" o más claramente "busca al carpintero en su taller, para hablarle cuando descanse de la azuela o del serrucho; con igual fin quiere estar entre la lesna y horma del zapatero; reposar sobre las rodillas del sastre; acompañar al agricultor en sus faenas, al apoyarse sobre el arado o al tenderse bajo la sombra del árbol. Quiere, por último, ir como a su propia casa a la morada del pobre y del obrero". El Mensajero del Pueblo, "Feliz quien sabe leer", 18 de junio de 1870 , Año I, N ${ }^{\circ} 2$.

(130) El Censo de 1875 arroja que un 25,9\% se desempeñaban como artesanos y labradores; un $21,5 \%$ eran gañanes; un $20 \%$ eran agricultores, mientras que un $15,4 \%$ realizaban trabajos domésticos. Cf. Anuario Estadístico, p. 118. Para bibliografía al respecto se puede revisar el estudio de Gabriel Salazar, Peones, labradores y proletarios: formación y crisis de la sociedad popular chilena del siglo XIX, Santiago, LOM, 2000

(131) En 1870, los gañanes ocupan el primer lugar; el segundo, los labradores. Los zapateros ocupan el tercero y los carpinteros el cuarto. Para 1876 los datos indican que gañanes ocupan el primer lugar; después carpinteros y labradores mientras que los zapateros ocupan el tercer lugar y los agricultores el cuarto. En el caso de las mujeres, en 1870 las costureras exceden con mucho a todas las demás. En 1876, las sirvientas equiparan a las costureras, formando las cifras más altas. Le siguen las cocineras y lavanderas.

(132) Anuario Estadístico, 1870-1871, "Criminalidad". 
personas. Debemos saber que esta difusión se hacía con mucha seguridad a través del capellán u otro sacerdote, quien pudo seleccionar las manos receptoras del semanario. En los demás centros de reclusión, los índices serían más bajos, pero siempre se contó con el factor de la "entrega personalizada". La red de circulación lograda tenía el objetivo de captar el mayor número de lectores, y que esa lectura fuese efectiva. La entrega en la casa, la distribución a personas clave que lo repartieran a "sujetos" claramente identificados, responde a una estrategia de recepción cuya coordinación permite pensar un alto nivel de efectividad.

\section{REFLEXIONES FINALES: ADIÓS AL SEMANARIO, BIENVENIDA AL DIARIO}

El Mensajero del Pueblo incluso en su primer año contó con un presupuesto muy estrecho, alcanzando a financiar apenas los costos que implicaba la publicación. La misma redacción señala al finalizar el primer año que tuvieron problemas en la gestión dando pasos inciertos y vacilantes (133). Las fuentes principales de ingresos provenían de los suscriptores y de los accionistas. Completaban sus entradas con la ayuda de al menos una veintena de personas que fueron denominados "bienhechores". Con el correr del tiempo la proporción se dio vuelta, siendo los benefactores los principales sostenedores del semanario. De hecho, si bien se lograba con las suscripciones una suma importante, no fue la necesaria para solventar las deudas, acumulándolas año a año. En el primer balance se contó con 17 pesos 17 centavos a favor, pero ya en las cuentas del segundo año se puede percibir lo que será la tónica de El Mensajero: el saldo total que se adeudaba ascendía a la suma de 826 pesos con 25 centavos. En el segundo año se generó esta deuda a pesar de que los gastos totales fueron menores $(5.354$ pesos, 38 centavos contra 6.635 pesos, 48 centavos del primer año). Para ello se tuvo que bajar el tiraje y la cantidad de reimpresiones de números agotados de un monto de 590 pesos a uno de 75 , además de reducir el monto asignado a los empleados destinados al reparto del semanario. La baja de los ingresos se explica en gran parte por el descenso de las suscripciones, tal como podemos apreciar en el gráfico 1 .

\section{Gráfico 1: Evolución de las suscripciones}

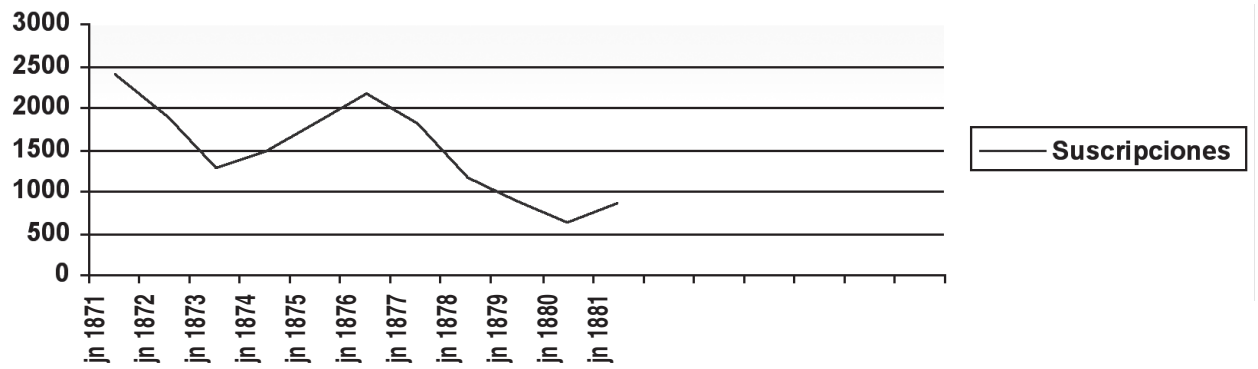

$\overline{\text { (133) El Mensajero }}$ del Pueblo, "A los lectores y accionistas de El Mensajero del Pueblo", Año I, No 30,31 de diciembre de 1870 . 
Decrecieron además los productos de las acciones abonadas al semanario. El primer año estas ascendían a 3.255 pesos, en el segundo a 2.380 , en el quinto a 1.805 para llegar en el décimo año a 786 pesos con 50 centavos. Esta situación puso en riesgo la existencia de la empresa. La primera crisis fue superada a costa de benefactores, pues no llegarían a obtener la cantidad máxima de suscripciones alcanzadas en 1871. Además, se reduciría el tiraje de los números publicados. Debemos anotar que en el primer año este alcanzó los seis mil ejemplares en varios de los primeros números, a pesar de que se presupuestó un tiraje de 4.500 ejemplares. En el segundo año fue de 4.500 ejemplares; el tercero, cuarto y quinto de 3.500 ; el sexto y el séptimo año el tiraje mínimo fue de 3.300 y el máximo de 4.000; el octavo de 3.000 y 3.300 ; el noveno de 2.000 y 3.000 , llegando al décimo año con un tiraje de 2.200 ejemplares. Tal como muestran las cifras la tendencia se hizo irremontable y poco debe haber ayudado la crisis económica del país agudizada en el 78. Después de ese año la situación fue crítica. Aparecerían algunos "benefactores extraordinarios" para la ocasión, como los presbíteros Joaquín Larraín Gandarillas, Alejandro Larraín, Juan Ignacio González, Rafael Eyzaguirre y Luis Campino que, en conjunto, aportaron 1.260 pesos (134). A pesar de esta ayuda extraordinaria quedó una deuda de 859 pesos 63 centavos con el editor Ramón Varela y 10 pesos con el Banco de la Alianza. El mismo panorama se repetiría en 1880. Para 1881, las noticias entregadas por el semanario ya hablan por sí solas (135). Los gastos de la empresa habían bajado a 2.266 pesos, pero aún así se adeudaban 840 pesos. En los años siguientes no se dará información alguna de las finanzas del semanario, lo que también habla por sí solo.

El aspecto económico no es todo y si incorporamos más factores al análisis lo que demuestra es un cambio en la producción periodística católica y más hipotéticamente en la demanda. La realidad de los años de 1880 era muy distinta a la de una década atrás. En 1870 todavía no se veía la radicalidad de las reformas políticoeclesiásticas ni se había hecho presente con mayor énfasis el proceso de urbanización y modernización. El semanario fue material insuficiente al ritmo de las necesidades. Tal como la redacción señala: "cada tiempo tiene sus peculiares necesidades y cada época sus obras de mayor simpatía (...). Ya no basta para la generalidad de los lectores del pueblo una hoja semanal en que se le dé cuenta del movimiento religioso, político y comercial; es menester una hoja diaria que lo imponga cada día de los sucesos más notables ocurridos tanto en el país como en el extranjero". La

(134) Otros "benefactores extraordinarios" aportaron con 175 pesos en total. Fueron los presbíteros Silverio Tignac, Nicanor de la Plaza y Pablo Martín, junto a las señoras Manuela y Justina Gandarillas.

(135) De hecho, el editor señala en términos categóricos: "EL MENSAJERO DEL PUEBLO se encuentra escaso de fondos y necesita organizar su oficina con toda economía, a fin de servir mejor a sus lectores y poder continuar en la tarea de proporcionar al pueblo una lectura sana e instructiva. POR ESTA RAZÓN, TENEMOS ORDEN TERMINANTE DE SUSPENDER EL PERIÓDICO A LOS QUE NO PAGUEN, SIN CONSIDERACIÓN DE NINGUNA ESPECIE.

La regla es general y la orden terminante, por lo cual nadie podrá considerarse ofendido. Necesitamos al presente el dinero para la vida del periódico, que no podemos imprimir con promesas de pago. Si tuviéramos fondos sobrantes, no seríamos tan exigentes. El mismo interés de nuestros lectores aconseja esta medida". Las mayúsculas son del editor del periódico. 
referencia era explícita a la aparición de El Chileno, pensado como ejemplo de la "petit presse". En su primer número publicado el 16 de diciembre de 1883 indicaban que aspiraban a alcanzar una "vasta circulación", con el ideal de convertirse en una hoja popular. La prensa en el período había rápidamente avanzado hacia su "modernización", hacia una prensa que fuese diaria, comercial y noticiosa, junto con ser fundamentalmente urbana. El Chileno nació más atento a las órdenes del mercado y de la cosa pública (136), por lo que rápidamente generó el "declinar sensible" de las suscripciones a El Mensajero, "a la par que El Chileno cuenta ya con más de 6.000 abonados en el corto período de su existencia”. En 1886 el semanario se adjuntó los domingos a la edición de El Chileno. Este último, por su parte, anunciaría todos los domingos que con él circulaba el número de El Mensajero del Pueblo, pero no lo hará más a partir del 16 de junio de 1886 a pesar de que el semanario apareció como fascículo todo el año. La razón de El Mensajero para insertarse a El Chileno era que así se llegaría "al seno de muchos más hogares y al santuario de muchas más almas sin que por esto pierda El Mensajero el carácter exclusivamente religioso, extraño a los vaivenes y lucha de la política con que hasta aquí hemos creído conveniente marcarlo, para quitar así todo pretexto a su introducción a las casas y establecimientos públicos como hospitales, cárceles o presidios" (137). Estas palabras debemos vincularlas con el contexto de crisis que ya tenía en esa época.

La nota de la redacción concuerda con los ideales principales que se propuso el semanario: no tocar la contingencia política ni hacerse parte en el apoyo de algún partido político. Eso no fue así del todo, pero en general la discusión de la política contingente no fue lo propio de El Mensajero si sopesamos todos los años de su vigencia. El semanario, dependiente de la Autoridad Eclesiástica desde 1878, debía ajustarse a los requerimientos de la jerarquía oficial. Al cambiar los sucesos políticos y con cada cambio de Arzobispo se produjeron modificaciones en la publicación. A la muerte de Monseñor Rafael Valentín Valdivieso y con la vacancia arzobispal el giro fue hacia el seguimiento del programa ultramontano y ya con Mariano Casanova el corte parece ser claro: El Mensajero del Pueblo no se adaptaba a la voz de la Iglesia oficial hacia los sectores de artesanos y obreros (138). Se necesitaban nuevas estrategias para llegar a un público nuevo y con requerimientos nuevos. Se necesitaban nuevas estrategias para una difusión de un catolicismo nuevo y con requerimientos nuevos.

(136) El Chileno, 16 de diciembre de 1883. Esta publicación, también popular, atendía más al proceso de modernización de la actividad periodística. Su redacción señala que son "el diario pequeño y barato que ha faltado siempre". El motivo de aparición es nuevamente "el desarrollo de la instrucción, que trae como consecuencia necesaria el interés por la cosa pública y el gusto por la lectura" y esto no solo en las clases ilustradas, sino que se convierte en una necesidad esencialmente popular. Indican que "el pueblo puede y quiere leer" y de ahí la necesidad de la "pequeña prensa".

(137) El Mensajero del Pueblo, 26 de diciembre de 1885.

(138) El Mensajero del Pueblo no pensó en dejar de existir. Las evidencias así lo demuestran. De hecho, en los últimos números de 1886, se indicaba a sus antiguos suscriptores que el semanario también llegaría en 1887 con El Chileno, pero que "podrán encargarlo separado para repartirlo en cárceles y hospitales", abonando el peso cincuenta centavos que costaba al año. No apareció en El Chileno, y no hay rastros de vida independiente. El Chileno no informó nada al respecto, cuestión que no es rara si vemos que dejó de percibir su presencia desde mediados del año anterior. 


\title{
RESUMEN
}

Este artículo está construido en base a la idea de que la jerarquía católica, sacerdotes y laicos entendieron los términos en que se promovían las ideas y proyectos en una sociedad moderna. Descubrieron que no estaban solos y ocuparon medios modernos de difusión, como la prensa, para difundir sus ideas y así contribuyeron también al logro de una sociedad plural. Así nació la prensa católica, escasamente estudiada en Chile. Aquí, junto con el proceso descrito, analizamos el caso de El Mensajero del Pueblo, el primer periódico con estabilidad considerable dirigido a sectores populares. Nos detenemos en sus ideas, pero también en su materialidad, en sus lectores y en los cambios que le influenció la sociedad en la que fue publicado. popular.

Palabras clave: Prensa Católica, Chile siglo XIX, El Mensajero del Pueblo, Prensa

\begin{abstract}
ABSTRAC
This article is built on the idea that the Catholic hierarchy, priests and lay people understood the terms in which the projects are spread in a modern society. They discovered that they were not alone and occupy the modern media as the press, contributed to building a pluralistic society. Thus was born the Catholic press, poorly studied in Chile. Here, together with the above process, we analyze the case of El Mensajero del Pueblo, the first newspaper with a considerable stability and led to the popular sectors. We stop in their ideas, but also in its materiality, its readers and the changes that had influenced by the society in which they were published.
\end{abstract}

Key words: Catholic Press, $19^{\text {th }}$-century Chile, El Mensajero del Pueblo, Popular Press. 